Atmos. Chem. Phys., 19, 11985-12006, 2019

https://doi.org/10.5194/acp-19-11985-2019

(C) Author(s) 2019. This work is distributed under

the Creative Commons Attribution 4.0 License.

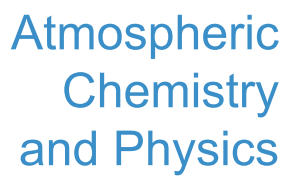

(c) (P)

\title{
Quantifying aerosol size distributions and their temporal variability in the Southern Great Plains, USA
}

\author{
Peter J. Marinescu ${ }^{1}$, Ezra J. T. Levin ${ }^{1}$, Don Collins ${ }^{2}$, Sonia M. Kreidenweis ${ }^{1}$, and Susan C. van den Heever ${ }^{1}$ \\ ${ }^{1}$ Department of Atmospheric Science, Colorado State University, Fort Collins, 80526, USA \\ ${ }^{2}$ Department of Chemical and Environmental Engineering, University of California, Riverside, 92521, USA
}

Correspondence: Peter J. Marinescu (peter.marinescu@colostate.edu)

Received: 9 February 2019 - Discussion started: 23 April 2019

Revised: 16 August 2019 - Accepted: 24 August 2019 - Published: 26 September 2019

\begin{abstract}
A quality-controlled, 5-year dataset of aerosol number size distributions (particles with diameters $\left(D_{\mathrm{p}}\right)$ from $7 \mathrm{~nm}$ through $14 \mu \mathrm{m}$ ) was developed using observations from a scanning mobility particle sizer, aerodynamic particle sizer, and a condensation particle counter at the Department of Energy's Southern Great Plains (SGP) site. This dataset was used for two purposes. First, typical characteristics of the aerosol size distribution (number, surface area, and volume) were calculated for the SGP site, both for the entire dataset and on a seasonal basis, and size distribution lognormal fit parameters are provided. While the median size distributions generally had similar shapes (four lognormal modes) in all the seasons, there were some significant differences between seasons. These differences were most significant in the smallest particles $\left(D_{\mathrm{p}}<30 \mathrm{~nm}\right)$ and largest particles $\left(D_{\mathrm{p}}>800 \mathrm{~nm}\right)$. Second, power spectral analysis was conducted on this long-term dataset to determine key temporal cycles of total aerosol concentrations, as well as aerosol concentrations in specified size ranges. The strongest cyclic signal was associated with a diurnal cycle in total aerosol number concentrations that was driven by the number concentrations of the smallest particles $\left(D_{\mathrm{p}}<30 \mathrm{~nm}\right)$. This diurnal cycle in the smallest particles occurred in all seasons in $\sim 50 \%$ of the observations, suggesting a persistent influence of new particle formation events on the number concentrations observed at the SGP site. This finding is in contrast with earlier studies that suggest new particle formation is observed primarily in the springtime at this site. The timing of peak concentrations associated with this diurnal cycle was shifted by several hours depending on the season, which was consistent with seasonal differences in insolation and boundary layer processes. Significant diurnal cycles in number concentra-
\end{abstract}

tions were also found for particles with $D_{\mathrm{p}}$ between 140 and $800 \mathrm{~nm}$, with peak concentrations occurring in the overnight hours, which were primarily associated with both nitrate and organic aerosol cycles. Weaker cyclic signals were observed for longer timescales (days to weeks) and are hypothesized to be related to the timescales of synoptic weather variability. The strongest periodic signals (3.5-5 and $7 \mathrm{~d}$ cycles) for these longer timescales varied depending on the season, with no cyclic signals and the lowest variability in the summer.

\section{Introduction}

Aerosol particles play a number of roles in the Earthatmosphere system, including impacting warm and cold cloud formation, solar and terrestrial radiation budgets, and human and environmental health. These impacts depend strongly on particle size, composition, and abundance. Aerosol number and mass concentrations arise from numerous sources and processes, including in situ chemical conversion, that shape the resulting chemical compositions and size distributions of the particle populations. Long-term observations provide insights into these processes by creating datasets that enable robust statistics regarding the typical temporal variations in aerosol properties. One such site with long-term aerosol measurements is the United States Department of Energy's Atmospheric Radiation Measurement's (ARM) Southern Great Plains (SGP) site. Located in north central Oklahoma, the ARM-SGP site (Sisterson et al., 2016) is influenced by a variety of aerosol types, sources, and transport pathways (e.g., Peppler et al., 2000; Sheridan et al., 2001; Andrews et al., 2011), making it an ideal location to 
study a wide range of aerosol processes and to characterize aerosol properties for a typical North American, rural, continental site.

Several studies have utilized the long-term aerosol data at the SGP site to study aerosol temporal variability. Sheridan et al. (2001) provided a climatology using 4 years of data of aerosol optical properties at the SGP site, as well as monthly, daily, and hourly statistics of total aerosol number concentrations for particles with diameters $\left(D_{\mathrm{p}}\right)$ between $\sim 10 \mathrm{~nm}$ and $3 \mu \mathrm{m}$. They found a diurnal cycle in total aerosol number concentrations that reached a minimum between 09:00 and 16:00 UTC, equivalent to 04:00 and 11:00 central daylight time (CDT; $\mathrm{CDT}=\mathrm{UTC}-5$ ), and reached a maximum between 19:00 and 22:00 UTC (14:00 and 17:00 CDT). They also found a weak weekly cycle in aerosol number concentrations, with minimum concentrations on Sunday. However, their study did not assess the diurnal or weekly variability on a seasonal basis. Most recently, Sherman et al. (2015) assessed the temporal variability of aerosol optical properties at four different sites in the United States, including the SGP site. They found that aerosol optical properties (e.g., scattering and absorption coefficients of aerosol with $D_{\mathrm{p}}<1 \mu \mathrm{m}$ ) had higher amplitude variations associated with seasonal timescales than with weekly or diurnal timescales at the individual sites, and they found that the seasonal variations at individual sites were larger than regional variations for the same season. Both findings support the need to understand aerosol processes on a seasonal basis. Sherman et al. (2015) was a follow-up study to, and generally consistent with, the results of Delene and Ogren (2002) and Sheridan et al. (2001), with all three studies focusing on aerosol optical properties at the SGP site. These studies demonstrated weak diurnal and weekly cycles of aerosol scattering and absorption that were significant depending on the season, with absorption having a stronger signal. Parworth et al. (2015) also provided some evidence of diurnal cycles in aerosol properties at the SGP site using 18 months of speciated aerosol mass concentration data $\left(D_{\mathrm{p}}\right.$ between $100 \mathrm{~nm}$ and $\left.1 \mu \mathrm{m}\right)$. Jefferson et al. (2017) related some of the results from these prior studies to the seasonal variability in aerosol scattering coefficient hygroscopic growth with 7 years of SGP data.

None of these prior studies of long-term variability in aerosol properties at the SGP site exploited the multiyear datasets of number size distributions available for the site, which allow for specific size ranges of aerosol particles to be studied. Number size distributions have been used to understand a variety of aerosol processes, such as new particle formation and growth (e.g., Dal Maso et al., 2005, 2007; Hallar et al., 2011; Pierce et al., 2014; Yu et al., 2015; Nieminen et al., 2018) and cloud processing of aerosol size distributions (e.g., Weingartner et al., 1999), at long-term aerosol observing sites around the world. Here, we present and analyze 5 years of aerosol number size distribution data $\left(D_{\mathrm{p}}\right.$ between $7 \mathrm{~nm}$ and $14 \mu \mathrm{m}$ ) from the SGP site. Specifically, we develop descriptions of annually and seasonally averaged sub- and super-micron size distributions and quantify their variability. Such descriptions are useful for validating aerosol models on a variety of scales and for selecting aerosol properties representative of the SGP site and the region. Representative aerosol size distributions at the SGP site are especially important for guiding the characteristics, location, and life cycle of aerosol particles in numerical modeling studies that try to represent the impacts of aerosol particles on the Earth system (e.g., Fridlind et al., 2017; Marinescu et al., 2017; Saleeby et al., 2016). Further, the long-term time series contain information on temporal cycles that can lead to insights into the aerosol sources and processes at the SGP site. In this work, we apply power spectral analysis to the time series of aerosol size distributions to determine the presence of significant temporal cycles in the aerosol data.

\section{Data}

The data presented here were collected at the SGP central facility (lat $=36.605$, lon $=-97.485$ ), representing a typical North American, rural, continental site. This site has many atmospheric science observations platforms, all located within an approximately $1 \mathrm{~km}^{2}$ area (Sisterson et al., 2016). This site is located within a large agricultural region in the central United States, which grows a variety of crops such as winter wheat, soybeans, cotton, corn, and alfalfa and has open pasture land (USDA-NASS Oklahoma Field Office, 2012). Therefore, agricultural aerosol sources frequently impact the aerosol conditions observed at the SGP site. There are a few local power plants (e.g., a coal-fired power plant in Red Rock, Oklahoma, $30 \mathrm{~km}$ to the southeast) and oil refineries (e.g., near Ponca City, Oklahoma, $35 \mathrm{~km}$ to the east), and Oklahoma City is approximately $130 \mathrm{~km}$ to the south. Besides local sources, the SGP site often encounters large concentrations of aerosol particles via long-range transport. High concentrations of aerosol particles associated with biomass burning in Central America and Mexico have been well documented in the spring and summer months (e.g., Peppler et al., 2000; Sheridan et al., 2001), although localized agricultural burning is also present (e.g., Parworth et al., 2015). Dust aerosol particles from both local sources and long-range transport have also been observed at the SGP site (e.g., Andrews et al., 2011).

A scanning mobility particle sizer (SMPS), which was part of the tandem differential mobility analyzer system (TDMA), measured particle size distributions between approximately 12 and $750 \mathrm{~nm}$ (Collins, 2010) during the 2009-2013 period at the SGP site. The size distributions were typically measured in 42-49 min time intervals, which were longer than typical SMPS measurements due to simultaneous operation of the instrument as a TDMA to measure aerosol hygroscopicity. In this study, the data were binned into $2 \mathrm{~h}$ intervals to create a more robust and evenly spaced dataset for analysis. For most of this time period, observations from 
an aerodynamic particle sizer (APS; TSI model 3321) were combined with the SMPS data to construct a number size distribution from $\sim 12 \mathrm{~nm}$ to $\sim 14 \mu \mathrm{m}$ with 215 size bins (SMPS + APS; ARM Climate Research Facility, 2010 and 2015). An assumed particle density of $2 \mathrm{~g} \mathrm{~cm}^{-3}$ was used to convert the aerodynamic diameter measured by the APS to mobility diameter prior to merging the two size distributions. A condensation particle counter (CPC; TSI model 3010; ARM Climate Research Facility, 2007 and 2011), which has $\mathrm{a} \sim 10 \%$ detection efficiency for particles of $7 \mathrm{~nm}$ diameter (Mertes et al., 1995), was connected to the same inlet as the SMPS + APS. The CPC data were used to augment the size distribution data at the smallest particle sizes, as described in the Appendix, to result in number concentrations for $D_{\mathrm{p}}$ ranging from $7 \mathrm{~nm}$ to $\sim 14 \mu \mathrm{m}$. The details of the ARM data streams used, the multiple quality control tests performed, the size distribution adjustments made that incorporated the CPC data, and a validation of these adjustments are also included in the Appendix, and the final data product is archived (Marinescu et al., 2019). Of the 5 years of archive data that were processed, over 3 years of data (15202 $2 \mathrm{~h}$ samples) passed our quality control process and were used in the subsequent analyses. The resulting dataset that was utilized in this study is shown in Fig. 1. Gaps in the data timeline represent time periods with unavailable data or data that did not pass quality control tests. The largest gap in the data (October 2010 to April 2011) was due to an internal leak in the CPC that was documented in the ARM dataset. While the SMPS + APS data were available during this period, the CPC adjustments could not be made, and therefore these data were excluded from this study.

\section{Seasonal variations in aerosol concentrations}

Several previous studies have found seasonal differences in aerosol properties at the SGP site (e.g., Andrews et al., 2011; Parworth et al., 2015; Sherman et al., 2015), and we therefore used the same season definitions (MAM, JJA, SON, and DJF) as these prior studies in order to facilitate comparisons. Throughout this paper, the terms MAM, JJA, SON, and DJF can be used interchangeably with spring, summer, autumn and winter, respectively. The 25th, 50th, and 75th percentile aerosol number $(N)$ size distributions were computed for each season, as well as for the entire 5-year period (ALL), and are shown in Fig. 2a; these number distributions were converted to surface area $(S)$ and volume $(V)$ size distributions as shown in Fig. $2 b$ and c. While similarities are evident in the seasonal size distributions' shapes and modes, several differences between the seasons can be seen in Fig. 2. JJA had a higher fractional contribution of particles with diameters larger than $50 \mathrm{~nm}$ as compared to the other seasons, which led to higher total surface area and volume concentrations in JJA. MAM and SON more frequently had larger concentrations of the smallest particles $\left(D_{\mathrm{p}}<20 \mathrm{~nm}\right)$, while DJF often had very few small particles. Four lognormal distribution modes were found to best fit the median size distributions (Fig. 3), where the lognormal distribution was defined as follows:

$N\left(\ln \left(D_{\mathrm{p}}\right)\right)=\frac{\mathrm{d} N}{\mathrm{~d} \ln \left(D_{\mathrm{p}}\right)}=\frac{N_{0}}{\ln \left(\sigma_{\mathrm{g}}\right) \sqrt{2 \pi}} e^{-\frac{\left(\ln \left(D_{\mathrm{p}}\right)-\ln \left(D_{\mathrm{m}}\right)\right)^{2}}{2 \ln ^{2}\left(\sigma_{\mathrm{g}}\right)}}$,

where $N_{0}$ is a total number concentration within the mode $\left(\mathrm{cm}^{-3}\right), \sigma_{\mathrm{g}}$ is the geometric standard deviation, and $D_{\mathrm{m}}$ is the median diameter $(\mu \mathrm{m})$. One lognormal mode, as opposed to two, was chosen to fit the coarse mode because the decrease in concentrations around $3 \mu \mathrm{m}$ was a data artifact, which is believed to have been caused by inaccurate size bin boundaries determined from the initial instrument calibration. The fitting was completed such that the mode parameters (Table 1) were converted between the number, surface area, and volume size distributions, and the integrated number and surface area were within $1 \%$ of the observed median values. The integrated volume values from the fitted distributions were $\sim 2 \%-4 \%$ higher than the median distributions values due to the aforementioned data artifact. The parameters for the number size distributions are shown in Table 1. The persistent but highly variable presence of a sub-30 nm mode, not completely resolved by the instrumentation at the SGP site, was likely associated with the growth of newly formed aerosol particles into the size ranges that were observed by the instrument suite used here. The next two modes approximate Aitken and accumulation modes with lognormal number distribution median diameters of 50-65 and 150-175 nm, respectively. Finally, one coarse mode represents the supermicron aerosol particles. It is important to note that the location and steepness of the drop-off in the largest aerosol mode may be related to the upper limit of the APS, as well as the decrease in inlet transmission efficiency for the largest particles, which was not corrected for in this dataset. The resulting four regions of the aerosol size distribution are demarcated by the vertical gray lines in Figs. 2 and 3 and represent particles with $D_{\mathrm{p}}$ between 7 and 30, 30 and 140, 140 and 800 , and $800 \mathrm{~nm}$ and $14 \mu \mathrm{m}$. The integrated number concentrations within these four size ranges $\left(N_{7-30 \mathrm{~nm}}, N_{30-140 \mathrm{~nm}}\right.$, $N_{140-800 \mathrm{~nm}}$, and $N_{800 \mathrm{~nm}+}$ ) are used for further analyses in this study. While the focus of this study is primarily on number concentrations, we have performed the same analyses for the same aerosol modes for integrated surface area and volume concentrations. Generally, the results were consistent amongst the integrated number, surface area, and volume distributions. These analyses are included in the Supplement for completeness.

To better quantify the variability within a season as well as the differences between seasons, Fig. 4 shows the distributions of total measured aerosol number concentrations of particles between $7 \mathrm{~nm}$ and $14 \mu \mathrm{m}\left(N_{\mathrm{T}}\right)$ for the entire period (ALL) and for each season, as well as the integrated number concentrations for each of the four size ranges. To es- 

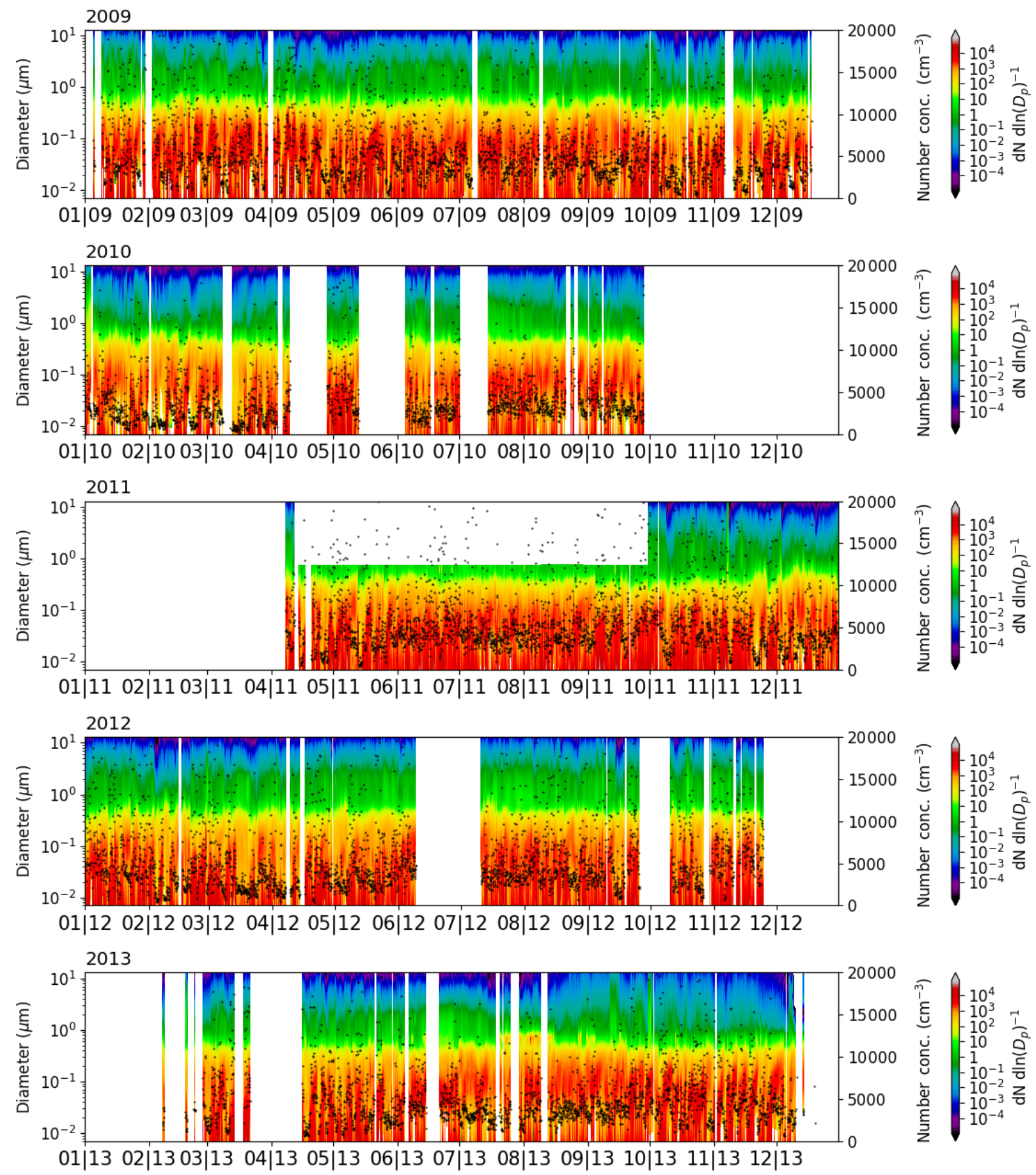

Figure 1. Time series of the final aerosol dataset used in this study following the quality control and the aerosol number size distribution adjustments, as described in the Appendix. Each row represents 1 year from 2009 through 2013. The shading represents the value of the number size distribution, $\mathrm{d} N \mathrm{~d} \ln D_{\mathrm{p}}^{-1}$, as a function of diameter (left axis), and the black dots represent the total integrated number concentrations $\left(N_{\mathrm{T}}\right.$, right axis). 

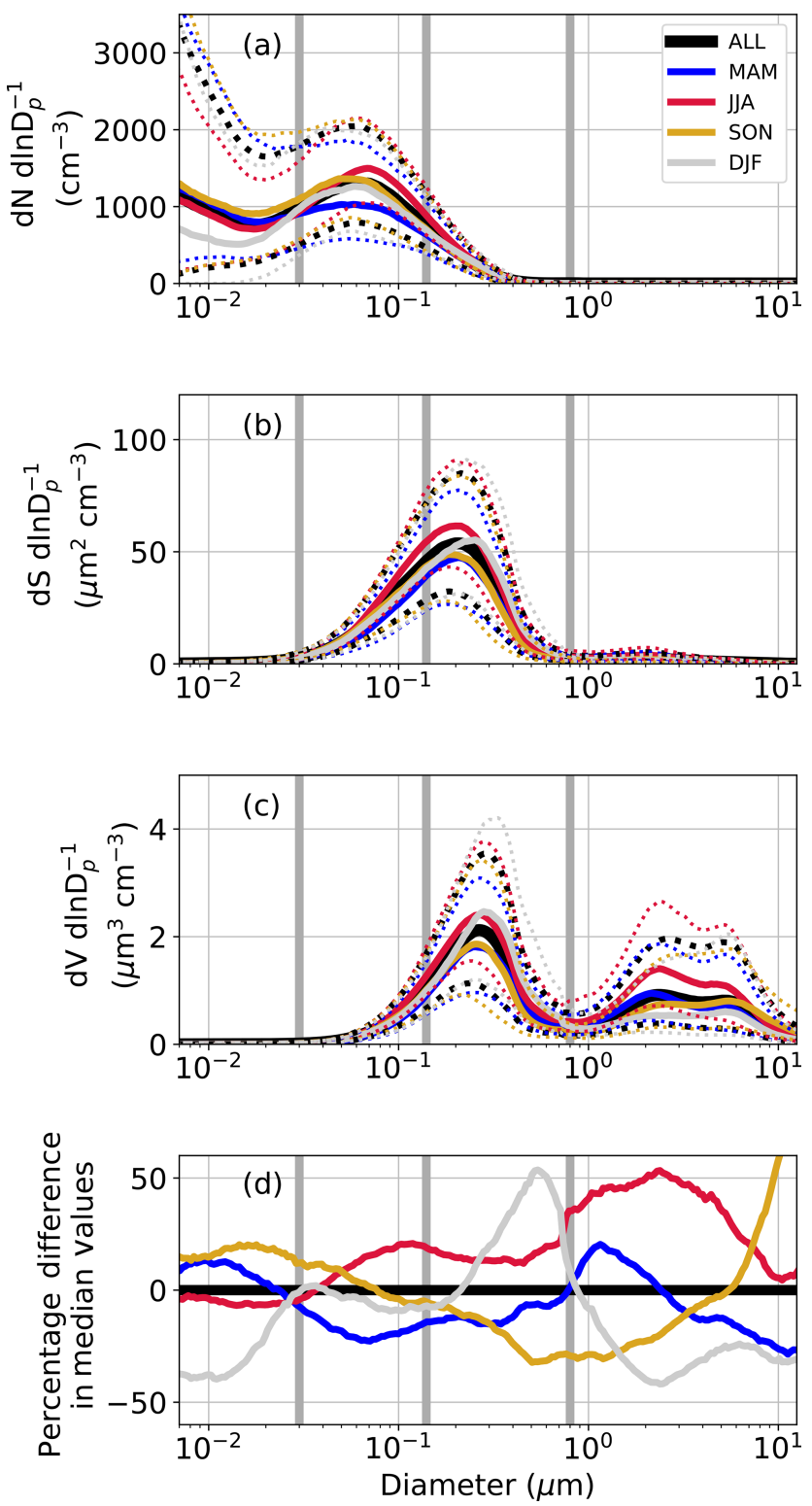

Figure 2. Aerosol size distributions for the entire time period and by season. (a) represents the number size distributions $\left(\mathrm{cm}^{-3}\right)$, (b) represents the surface area size distributions $\left(\mu \mathrm{m}^{2} \mathrm{~cm}^{-3}\right)$, and (c) represents the volume size distributions $\left(\mu \mathrm{m}^{3} \mathrm{~cm}^{-3}\right)$. The solid colored lines depict the median values, and the dotted lines depict the 25 th and 75 th percentiles. (d) represents the percentage difference in the median size distributions for each season with respect to the entire period (ALL). The vertical gray lines demarcate the four separate regions of the size distribution that were used for further analyses in this study.

timate the statistical significance of the differences between the seasonal distributions, a simple bootstrapping technique was used. For each season, the effective sample size was estimated using lag-1 autocorrelations (Leith, 1973; Wilks, 2011) since the $2 \mathrm{~h}$ samples were not independent. This typically reduced the sample size by a factor of $0.04-0.29$, de-
Table 1. Parameters for each mode of the fitted lognormal distributions for the number size distributions shown in Fig. 3. $N_{0}$ represents the amplitude of the lognormal distribution and the total number concentration within the mode $\left(\mathrm{cm}^{-3}\right), D_{\mathrm{m}}$ represents the median diameter $(\mu \mathrm{m})$, and $\sigma_{\mathrm{g}}$ represents the geometric standard deviation, all as denoted in Eq. (1) in the text.

\begin{tabular}{|c|c|c|c|c|c|}
\hline & ALL & MAM & JJA & SON & DJF \\
\hline \multicolumn{6}{|c|}{ Mode 1} \\
\hline$N_{0}$ & 2606 & 3083 & 2171 & 2910 & 1911 \\
\hline$D_{\mathrm{m}}$ & 0.00530 & 0.00550 & 0.00550 & 0.00550 & 0.00450 \\
\hline$\sigma_{\mathrm{g}}$ & 2.80 & 2.80 & 2.80 & 2.80 & 2.80 \\
\hline \multicolumn{6}{|c|}{ Mode 2} \\
\hline$N_{0}$ & 1883 & 1406 & 2049 & 1896 & 1929 \\
\hline$D_{\mathrm{m}}$ & 0.05866 & 0.05426 & 0.06460 & 0.05459 & 0.05343 \\
\hline$\sigma_{\mathrm{g}}$ & 1.82 & 1.81 & 1.76 & 1.78 & 1.84 \\
\hline \multicolumn{6}{|c|}{ Mode 3} \\
\hline$N_{0}$ & 352 & 395 & 452 & 391 & 362 \\
\hline$D_{\mathrm{m}}$ & 0.16624 & 0.15416 & 0.16189 & 0.15605 & 0.17262 \\
\hline$\sigma_{\mathrm{g}}$ & 1.53 & 1.56 & 1.56 & 1.54 & 1.54 \\
\hline \multicolumn{6}{|c|}{ Mode 4} \\
\hline$N_{0}$ & 0.791 & 1.244 & 1.100 & 0.576 & 0.486 \\
\hline$D_{\mathrm{m}}$ & 0.82355 & 0.69573 & 0.85788 & 0.87508 & 0.88354 \\
\hline$\sigma_{\mathrm{g}}$ & 1.97 & 1.99 & 1.93 & 2.00 & 1.94 \\
\hline
\end{tabular}

pending on the lag-1 autocorrelation of each integrated variable in each season. A total of 10000 random samples of a size equal to the effective sample size for each season were drawn, with replacement, from the ALL distribution. For each of the 10000 random samples, the mean, median, interquartile range (IQR), and the $5 \%$ and $95 \%$ percentile range (R595) were calculated, resulting in a distribution of these summary statistics for the 10000 ALL random samples. Then, the mean, median, IQR, and R595 were computed for each season's data and were compared to the distribution of the same statistic for the 10000 ALL random samples. For example, the DJF mean concentration for $N_{\mathrm{T}}\left(5195 \mathrm{~cm}^{-3}\right)$ was equal to the 1 st percentile of the 10000 ALL random sample means (gray diamond in the top row of Fig. 4f). In other words, when 10000 random samples of the ALL $N_{\mathrm{T}}$ data were taken with the effective sample size of the DJF $N_{\mathrm{T}}$ data, only $1 \%$ of those 10000 samples had means smaller than the DJF mean, suggesting the DJF mean value is significantly different from (in this case significantly less than) the ALL mean value. The same process was completed for the median, IQR, and R595 statistics for each season. Bold distribution characteristics in Fig. 4a-e represent instances in which the key statistic was less than the 5th percentile or greater than the 95th percentile of the distribution of random samples from the ALL data (Fig. 4f), suggesting significantly lower and higher values than the ALL data, respectively. It 

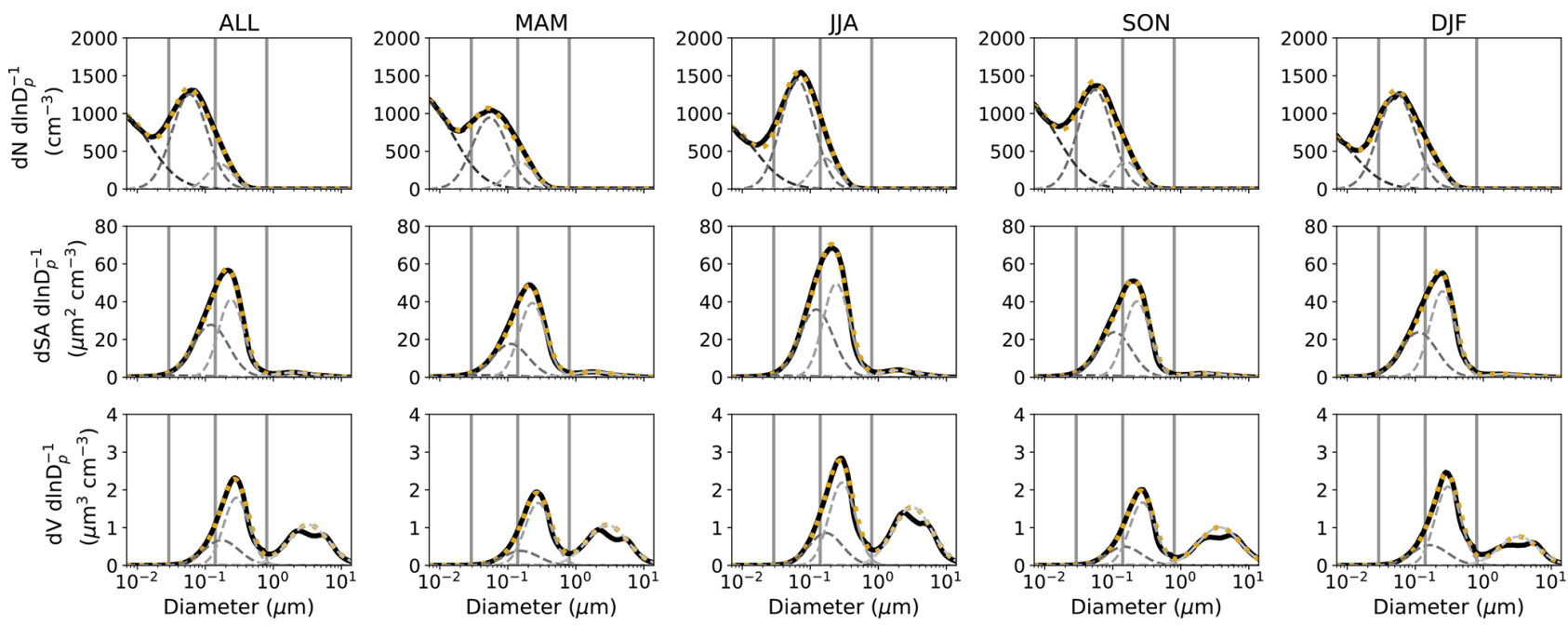

SGP Data

\#... Modes combined

---. Mode 1

---. Mode 2

--.. Mode 3

Mode 4

Figure 3. Median distributions from each season (black) fitted with four lognormal distributions (modes). The columns (left to right) represent the time periods ALL, MAM, JJA, SON, and DJF, respectively. The rows (top to bottom) represent the number, surface area, and volume size distributions, respectively. The vertical gray lines demarcate the four separate regions of the size distribution that were used for further analyses in this study.

(a) $\mathrm{N}_{T}$

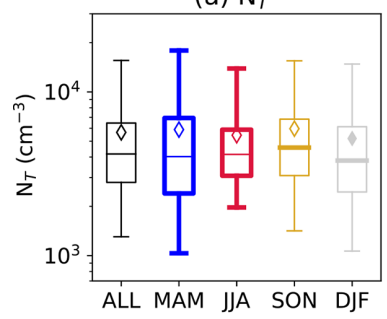

(d) $\mathrm{N}_{140-800 \mathrm{~nm}}$

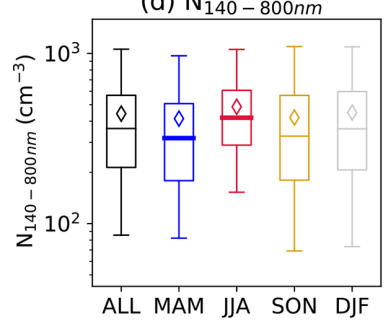

(b) $\mathrm{N}_{7-30 \mathrm{~nm}}$

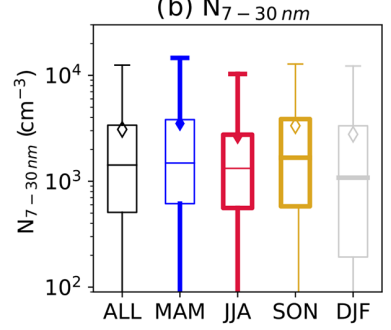

(e) $\mathrm{N}_{800 \mathrm{~nm}+}$

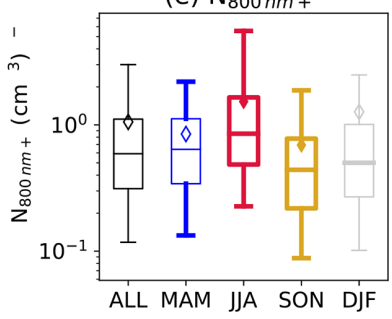

(c) $\mathrm{N}_{30-140 \mathrm{~nm}}$
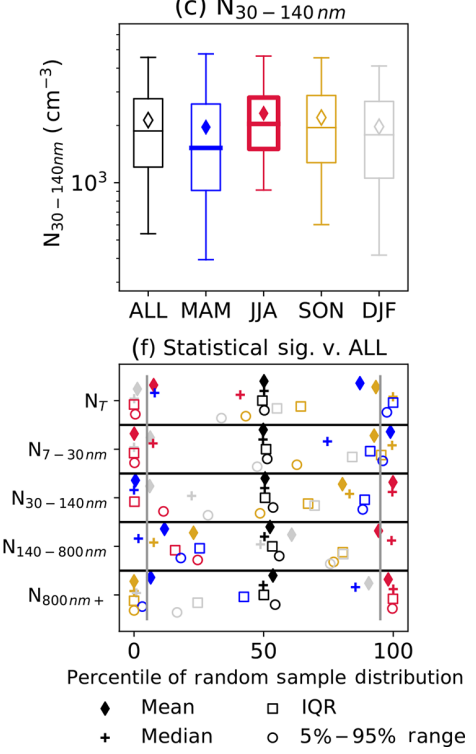

Figure 4. Distributions of integrated number concentrations for the entire size distribution (a) and for the four size ranges (b-e, $N_{7-30 \mathrm{~nm}}$, $N_{30-140 \mathrm{~nm}}, N_{140-800 \mathrm{~nm}}$, and $N_{800 \mathrm{~nm}+}$ ), shown as box-plot diagrams. Data are shown for the entire time period (ALL) and by season. The boxes represent the interquartile ranges separated into two boxes by the median values, the diamonds represent the mean values, and the lines extending from the boxes represent the 5th and 95th percentiles. Bold lines and solid symbols in panels (a) through (e) represent differences between the seasonal and ALL variables that are statistically significant at the $95 \%$ level, as described in the text and shown in panel (f). The vertical gray lines in (f) are the 5th and 95th percentiles. 
is important to note that these are arbitrary levels of significance, and Fig. $4 \mathrm{f}$ shows the entire range of percentile values for each distribution statistic for all the integrated number variables. We have also included the same analysis for surface area and volume distributions in the Supplement.

In terms of total aerosol number concentrations $\left(N_{\mathrm{T}}\right.$, Fig. $\left.4 \mathrm{a}\right)$, the DJF mean $\left(5195 \mathrm{~cm}^{-3}\right)$ and median $\left(3808 \mathrm{~cm}^{-3}\right)$ concentrations were significantly lower than ALL, while the median SON value $\left(4572 \mathrm{~cm}^{-3}\right)$ was significantly higher than the other time periods. MAM was the most variable season, with a significantly different IQR and R595, while JJA was significantly less variable than the other time periods, with a lower IQR and R595. For example, the R595s were $14286,16889,11957,14072$, and $13772 \mathrm{~cm}^{-3}$ for ALL, MAM, JJA, SON, and DJF, respectively. These R595 results are consistent with the results of Sheridan et al. (2001), particularly their Fig. 5a, which shows the largest breadth of number concentrations in the spring months and smallest breadth in the summer months. These results suggest the importance of seasonal synoptic-scale weather variability with respect to $N_{\mathrm{T}}$ variability. For example, Andrews et al. (2011) used back trajectories to determine the transport pathways of aerosol to the SGP site, and in the MAM, SON, and DJF periods there were high frequencies of pathways coming both from the northwest and from the south or southeast, while in JJA the pathways were primarily from the same direction (southerly), resulting in lower variability in observed aerosol properties. Furthermore, several studies have documented episodically high concentrations of aerosol particles at the SGP site in MAM from local agricultural and wildfire sources and from the transport of biomass burning aerosol into this region from various parts of North America (e.g., Peppler et al., 2000; Wang et al., 2009).

For $N_{7-30 \mathrm{~nm}}$, the MAM mean value $\left(3512 \mathrm{~cm}^{-3}\right)$ was the largest of all seasons, while the SON median value $\left(1669 \mathrm{~cm}^{-3}\right)$ was the largest, demonstrating the MAM had the most extreme high concentrations of particles within this smallest size mode, while high concentrations were more frequent during SON. JJA had a significantly lower mean $\left(2639 \mathrm{~cm}^{-3}\right)$ value for total concentrations within this mode, as well as significantly lower variability in terms of lower IQR $\left(2196 \mathrm{~cm}^{-3}\right)$ and $\mathrm{R} 595\left(10315 \mathrm{~cm}^{-3}\right)$, as compared to the other time periods, which may have been a result of a consistent coagulation sink due to the higher concentrations of larger aerosol (Fig. 2). DJF had the highest frequency of low concentrations, which lowered the median concentration $\left(1080 \mathrm{~cm}^{-3}\right)$. This smallest size mode was also associated with the highest variability of all the aerosol modes (in terms of absolute values) as seen by the breadth of the R595 (spanning several orders of magnitude). This large variability was likely caused by the frequent bursts of high concentrations associated with new particle formation and the growth of these newly formed particles into the size ranges observed in this study, although uncertainties associated with the obser- vations of particles within this smallest mode may have also contributed to this variability, as discussed in the Appendix.

For $N_{30-140 \mathrm{~nm}}$, a shift in seasonal trends occurred. JJA, which had significantly lower concentrations than ALL for $N_{7-30 \mathrm{~nm}}$, had a significantly larger mean $\left(2315 \mathrm{~cm}^{-3}\right)$ and median $\left(2037 \mathrm{~cm}^{-3}\right)$ concentration, which could be related to enhanced precursor concentrations in the summer months (e.g., Parworth et al., 2015). A similar reversal of trends occurred for MAM, which had a significantly lower mean $\left(1959 \mathrm{~cm}^{-3}\right)$ and median $\left(1523 \mathrm{~cm}^{-3}\right)$ concen-

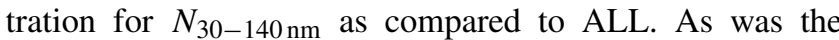
case for $N_{7-30 \mathrm{~nm}}$, JJA was the least variable season for $N_{30-140 \mathrm{~nm}}$. The seasonal trends for $N_{140-800 \mathrm{~nm}}$ were similar to $N_{30-140 \mathrm{~nm}}$, albeit with smaller differences between the seasons.

There was large seasonal variability associated with concentrations of the largest particles $\left(N_{800 \mathrm{~nm}+}\right)$. JJA had a significantly higher mean $\left(1.53 \mathrm{~cm}^{-3}\right)$ and median $\left(0.85 \mathrm{~cm}^{-3}\right)$ concentration and had significantly higher variability (R595 of $5.32 \mathrm{~cm}^{-3}$ ), as compared to the other seasons. On the other hand, SON had a significantly lower mean $\left(0.69 \mathrm{~cm}^{-3}\right)$ and median $\left(0.44 \mathrm{~cm}^{-3}\right)$ concentration and significantly lower variability (R595 of $1.79 \mathrm{~cm}^{-3}$ ), as compared to ALL. MAM also had significantly lower variability (R595 of $2.07 \mathrm{~cm}^{-3}$ ). Interestingly, while DJF had a significantly low median concentration $\left(0.50 \mathrm{~cm}^{-3}\right)$ as compared to ALL, its mean concentration $\left(1.27 \mathrm{~cm}^{-3}\right)$ was larger than the ALL data mean $\left(1.06 \mathrm{~cm}^{-3}\right)$, due to the presence of a few time periods with very high concentrations within this mode. These $N_{800 \mathrm{~nm}+}$ results are generally consistent with prior studies (Sheridan et al., 2001; Andrews et al., 2011), which have attributed the seasonal presence of coarse mode aerosol particles to dust, both from local sources and transported into the region.

\section{Sub-seasonal cycles within aerosol number concentrations}

\subsection{Methods}

While the prior section was focused on seasonal differences in the aerosol size distribution, the focus of this section is the investigation of the sub-seasonal variability on timescales from several hours to several weeks using power spectral analysis. Power spectral analysis is a computational tool that fits a range of harmonic functions of varying frequencies to a data series using Fourier sums and then calculates the amount of total variance in a data series that can be explained by each harmonic function, each associated with a specific frequency and period. The amount of variance explained by each frequency is often termed the power spectrum. The length and resolution of the data series on which the power spectral analysis is computed determines the frequencies of cycles within the dataset that can be resolved and tested. The cycle periods $(T)$ and frequencies $(f)$ that are resolved in such analyses are 

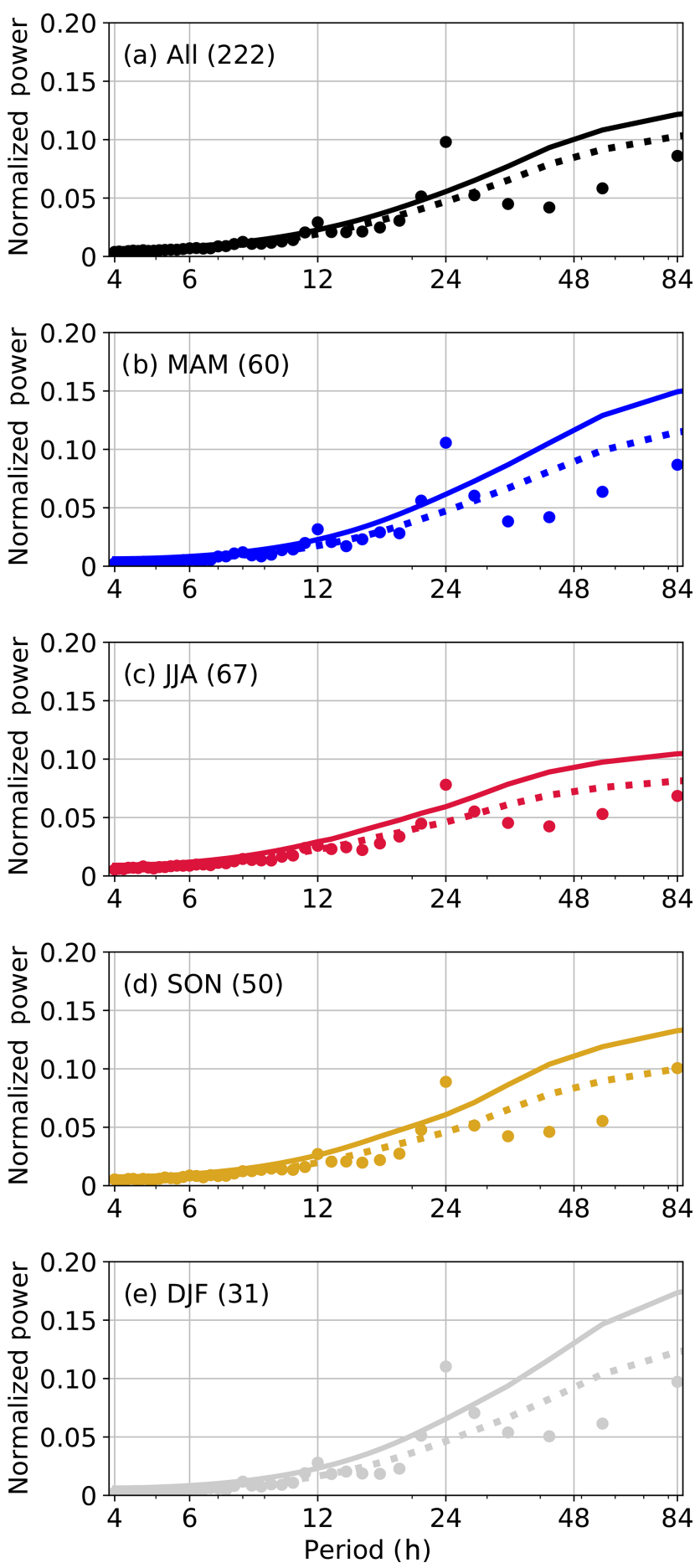

Figure 5. Normalized power spectra for $N_{\mathrm{T}}$ for the entire period (a) and by season (b-e). The dots represent power associated with the data. The dashed lines represent an estimate of the red noise power spectrum for each dataset, and the solid lines represent the $99 \%$ significance testing level, as described in the text. The values in the parentheses are the number of weekly data chunks used in this analysis. given by the following:

$$
T=\frac{1}{f}=\frac{M}{k}, \quad \text { where } \quad k=1, \ldots, \frac{M}{2},
$$

where $M$ is the length of the data series.

The aerosol number concentration data were separated into the four seasons, as was done in Sect. 3. Then, the data were further partitioned into years to ensure a continuous time series, a requirement for spectral analysis. This partitioning resulted in the following 21 data subsets JF2009, MAM-2009, JJA-2009, SON-2009, DJF-2010, ..., SON-2013, D-2014. The DJF seasons included the December month of the prior year to create the continuous time period. For each of these 21 subsets, anomalies were first recalculated as differences from the subset mean and the anomalous data were then separated into smaller data chunks ( 7 and $28 \mathrm{~d}$ in this study) for spectral analysis. Two choices for the length of the data series $(M)$ were used in order to study different temporal scales. The resulting power spectra were averaged together by season for all the years and tested for significance. Separating each of the 21 seasonal subsets into smaller data chunks and averaging the resulting power spectra together increased the robustness of the analysis. Because of the difficulties in fitting harmonic functions at the edges of finite data, a Hanning window was applied to smooth the data. However, it should be noted that using such a smoothing method also limited the smallest frequency (largest period) that could be accurately detected. In order to account for this smoothing and to incorporate all the data, a $50 \%$ overlap window was also applied to the data.

To determine the statistical significance of the averaged power spectra, red noise spectra were estimated from the data. For each length $M$ data chunk without any missing values, the lag-1 autocorrelation $\left(r_{\text {lag } 1}\right)$ was determined. The red noise power spectra were then computed for each data chunk using the following formula from Gilman et al. (1963):

red noise $(f, r)=\frac{1-r_{\operatorname{lag} 1}^{2}}{1-2 r_{\operatorname{lag} 1} \cos (2 \pi f)+r_{\operatorname{lag} 1}^{2}}$.

These red noise power spectra were averaged together for each season. The $99 \%$ confidence level was calculated using the $\mathrm{F}$ distribution, with the test statistic being the ratio of variances (i.e., power) of the actual data to that of red noise at the same frequencies. The degrees of freedom used for calculating the $99 \%$ confidence level were based on the number of individual power spectra that were averaged together multiplied by 2.8 (Welch, 1967) for the actual data spectra and 1000 for the red noise spectra. Choosing a relatively large value (1000) for the red noise degrees of freedom demonstrates confidence in our red noise spectrum formulation. However, other values (100 and 500) were tested and resulted in no qualitative changes to the results presented herein. 


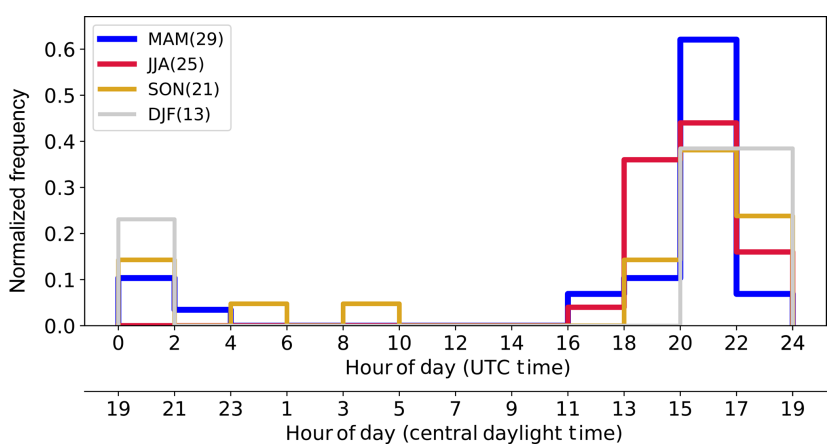

Figure 6. Normalized frequency of the daily time of peak concentrations associated with the $24 \mathrm{~h}$ cycle in $N_{\mathrm{T}}$. This figure only includes weekly data chunks that had normalized power associated with the $24 \mathrm{~h}$ cycle greater than that of the corresponding seasonal estimate of the red noise spectrum power. The numbers in parentheses represent the number of weekly data chunks that met this criterion.

\subsection{Hourly to daily cycles of aerosol number concentrations}

To determine the hourly to daily power spectra, the data series were binned and averaged over $2 \mathrm{~h}$ intervals, with a length of the data series $(M)$ of $7 \mathrm{~d}$, thus resolving $4 \mathrm{~h}$ to $3.5 \mathrm{~d}$ cycles in the data. Missing data for up to $6 \mathrm{~h}$ were interpolated linearly from surrounding values. The resulting power spectra for total aerosol concentrations $\left(N_{\mathrm{T}}\right)$, for the entire period and by season, are shown in Fig. 5. The strongest cycle in this aerosol dataset was the $24 \mathrm{~h}$ or diurnal cycle. This was present in the average power spectrum for each season and for the entire dataset and always exceeded the $99 \%$ significance level as compared to red noise. In other words, we can state with very high confidence that the diurnal cycle in these data did not arise from random fluctuations as represented by a red noise time series. Furthermore, $48 \%, 37 \%, 42 \%$, and $42 \%$ of the total number of weekly data chunks had power associated with the diurnal cycle greater than that of red noise for MAM, JJA, SON, and DJF, respectively. Therefore, while MAM had slightly more frequent diurnal cycles in $N_{\mathrm{T}}$, this diurnal cycle was a year-round phenomenon at the SGP site. All seasons, except JJA, also exhibited a $12 \mathrm{~h}$ cycle in $N_{\mathrm{T}}$ at $99 \%$ confidence. We will first focus on the $24 \mathrm{~h}$ cycle and then examine the $12 \mathrm{~h}$ cycle in the following sections.

\subsubsection{The $24 \mathrm{~h}$ (diurnal) cycle of aerosol particles}

The subset of weekly data chunks that had power associated with the diurnal cycle greater than that of red noise was used to calculate the timing of the maximum and minimum aerosol concentrations associated with the diurnal cycle. Although the focus here will be on the timing of the maximum concentrations, the timing of minimum concentrations can be calculated by shifting the maximum concentration timing by half of the period of interest (i.e., for the diurnal cycle, a
$12 \mathrm{~h}$ shift between maximum and minimum concentrations). Figure 6 shows the normalized frequency of the maximum aerosol concentrations associated with the diurnal cycle as a function of time. The maximum aerosol number concentrations associated with the diurnal cycle primarily occurred between 18:00 and 02:00 UTC (13:00 and 21:00 CDT). While the timing of the diurnal cycle peak was generally in the local afternoon and evening hours for all seasons, the exact timing shifted between the seasons. The peak in the JJA diurnal cycle occurred several hours earlier (peak concentrations around 18:00-22:00 UTC or 13:00-17:00 CDT) than the peak in the annual average (20:00-22:00 UTC or 15:00 17:00 CDT), and the peak for DJF was shifted towards the later hours (peak concentrations from 20:00 to 02:00 UTC or 15:00-21:00 CDT) relative to the annual average.

To better understand the aerosol processes related to this diurnal cycle in $N_{\mathrm{T}}$ and to test whether there were sizedependent cycles, power spectra for the integrated aerosol number concentrations for each of the four modes of the aerosol size distribution $\left(N_{7-30 \mathrm{~nm}}, N_{30-140 \mathrm{~nm}}, N_{140-800 \mathrm{~nm}}\right.$, and $N_{800 \mathrm{~nm}+}$ ) were computed and are shown in Fig. 7 . There were statistically significant diurnal cycles for all seasons for $N_{7-30 \mathrm{~nm}}$ and $N_{140-800 \mathrm{~nm}}$. For $N_{30-140 \mathrm{~nm}}$, JJA had the strongest diurnal cycle, although the diurnal cycles for $N_{30-140 \mathrm{~nm}}$ were relatively weaker, in comparison to red noise, than those for $N_{7-30 \mathrm{~nm}}$ and $N_{140-800 \mathrm{~nm}}$. For the largest particles $\left(N_{800 \mathrm{~nm}+}\right)$, there was no consistent diurnal cycle above that of red noise, although there was some enhanced power in JJA. These results were generally consistent for the integrated surface area and volume concentrations unless otherwise noted.

As was done for the total integrated number concentration for the entire size distribution, $N_{\mathrm{T}}$, the timing of peak concentrations associated with the diurnal cycle was calculated for each of the four aerosol size ranges (Fig. 8). Because small particles often accounted for the majority of the total number concentrations, $N_{7-30} \mathrm{~nm}$ was the primary driver of the diurnal signal in the total aerosol number concentrations $\left(N_{\mathrm{T}}\right.$, Fig. 5). This was further corroborated by the fact that the timing of the diurnal cycle peak concentrations for $N_{7-30 \mathrm{~nm}}$ occurred at approximately the same times as that for $N_{\mathrm{T}}$ (compare Fig. 8a with Fig. 6). Aerosol particles in this smallest size range are typically presumed to have originated in new particle formation (NPF) events, followed by growth of those newly formed particles to sizes that can be detected by the instruments used in this study. Niemenen et al. (2018) assessed NPF at many sites around the world, including the SGP site, and found that the presence and growth of these small particles most frequently occurred in MAM ( $25 \%$ of the time) at the SGP site but were much less frequent in the other seasons (10\% in SON, $8 \%$ in DJF, and $4 \%$ in JJA). While our results corroborate the high concentrations of small particles in MAM, they also indicated consistent diurnal cycles of $N_{7-30} \mathrm{~nm}$ throughout the year. A total of $55 \%, 46 \%, 56 \%$, and $48 \%$ of the weekly $N_{7-30 \mathrm{~nm}}$ data 

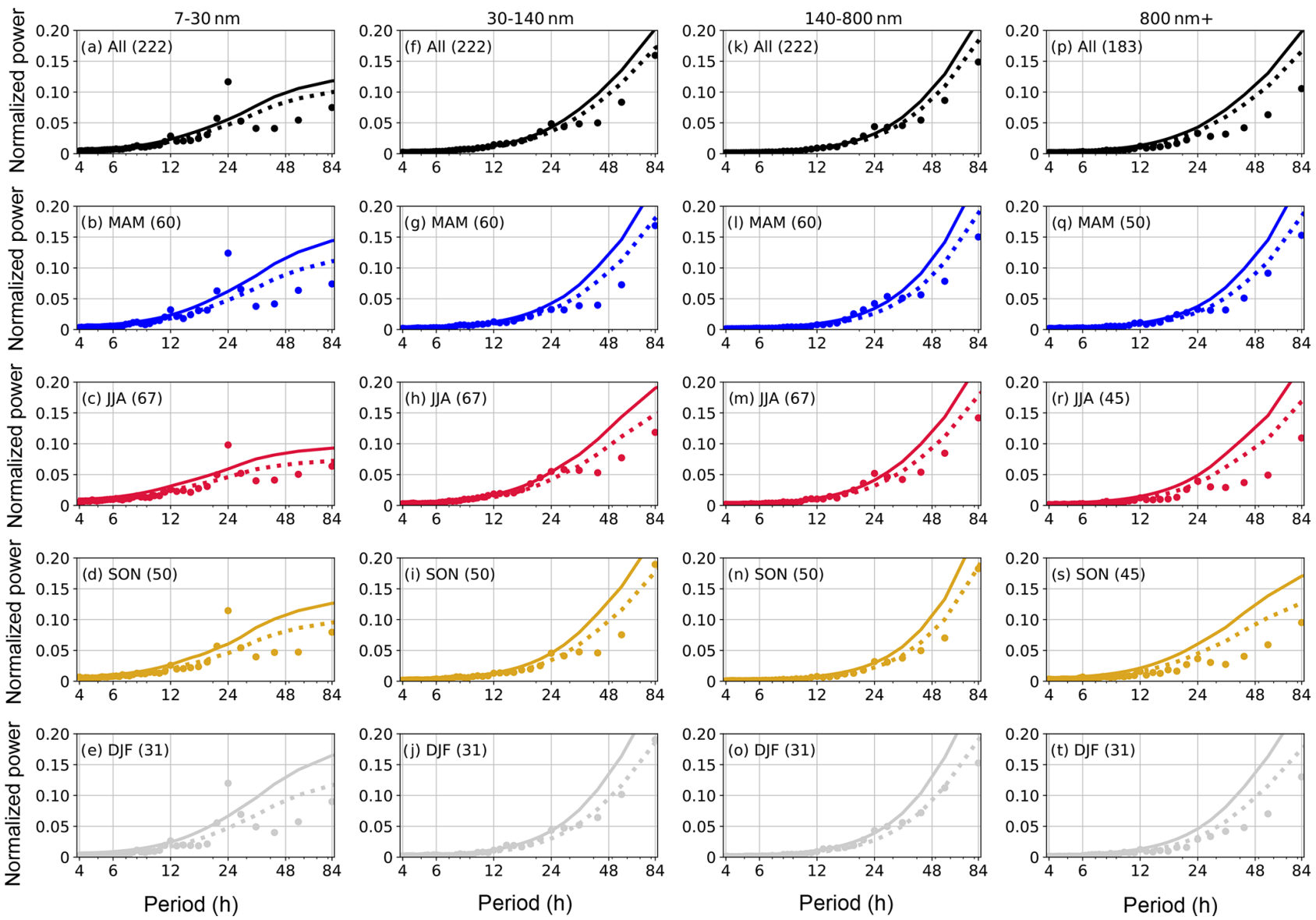

Figure 7. Normalized power spectra for $N_{7-30 \mathrm{~nm}}, N_{30-140 \mathrm{~nm}}, N_{140-800 \mathrm{~nm}}$, and $N_{800 \mathrm{~nm}+}$ for the entire period and by season. The descriptions of the symbols used are the same as in Fig. 5.

chunks had $24 \mathrm{~h}$ cycles with power above that of red noise for MAM, JJA, SON, and DJF, respectively. Reasons for differences between this study and the study of Niemenen et al. (2018) are likely related to the incorporation of the CPC data and the adjustments made to the aerosol size distribution at these smaller sizes in this study (see Appendix), but are also related to the metric used to assess the presence of these small particles.

The broadly consistent timing of the diurnal cycle in $N_{7-30 \mathrm{~nm}}$ throughout the year (local afternoon and evening) may suggest similar formation, growth, and/or transport mechanisms for aerosol with $D_{\mathrm{p}}$ between 7 and $30 \mathrm{~nm}$. The several-hour seasonal shift in the timing of the peak concentrations between seasons may also help to elucidate some of the processes leading to observations of elevated $N_{7-30 \mathrm{~nm}}$ at the SGP surface site. At the SGP site, the height of the atmospheric boundary layer reaches a specified altitude earlier in JJA and later in DJF, with MAM and SON falling in between (Liu and Liang, 2010; Delle Monache et al., 2004), which is consistent with the seasonal shift in the timing of the $N_{7-30} \mathrm{~nm}$ diurnal cycle. If the source region of these small particles were above the surface, then this shift in $N_{7-30 \mathrm{~nm}}$ timing could also be impacted by the rate of vertical mixing and transport in the boundary layer in the different seasons. Chen et al. (2018) found that it took $\sim 0.5-1.0 \mathrm{~h}$ to vertically mix small aerosol particles from $\sim 400 \mathrm{~m}$ above the ground to the surface during a new particle formation event on 12 May 2013 that occurred in an unstable atmosphere (lapse rate of $0.9-1.2^{\circ} \mathrm{C}$ per $100 \mathrm{~m}$ up to $400 \mathrm{~m}$ a.g.l.). This vertical mixing of aerosol from heights above the surface to the surface would take longer in boundary layers that are more statically stable, such as those typical in winter, and hence may also help to explain the seasonal shift in the timing of the $N_{7-30 \mathrm{~nm}}$ diurnal cycle.

To assess the boundary layer evolution for the 5 years that are focused on in this study, boundary layer heights, estimated from radiosonde data, were examined (ARM Climate Research Facility, 2001). During 2009-2013, radiosondes were typically launched four times a day, at approximately 05:30, 11:30, 17:30, and 23:30 UTC. Boundary layer heights were estimated using the bulk Richardson number and a threshold of 0.25 (Seibert et al., 2000); however, additional boundary layer height estimates (Sivaraman et al., 2013) were also tested and resulted in qualitatively similar 

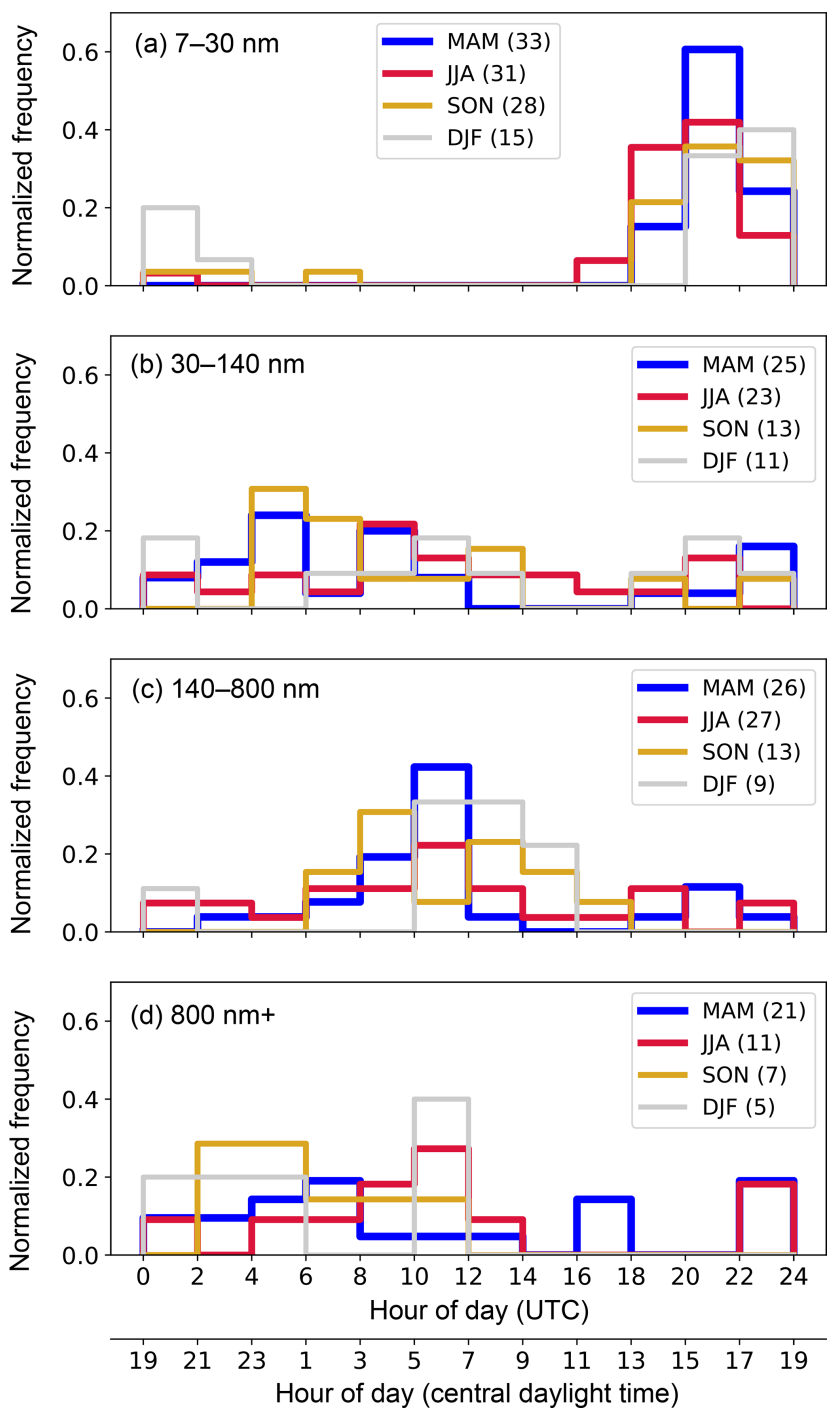

Figure 8. Normalized frequency of the daily time of peak concentrations associated with the $24 \mathrm{~h}$ cycle in the different modes of the aerosol number size distribution. (a)-(d) represent $N_{7-30 \mathrm{~nm}}$, $N_{30-140 \mathrm{~nm}}, N_{140-800 \mathrm{~nm}}$, and $N_{800 \mathrm{~nm}+}$, respectively. The description of the figure is the same as in Fig. 6.

statistics. The data were then filtered to only include the weekly data when the power associated with the $N_{7-30 \mathrm{~nm}}$ diurnal cycle was within the top $25 \%$ of the data (high diurnal power, circles in Fig. 9) and to include weekly data when the power associated with the $N_{7-30 \mathrm{~nm}}$ diurnal cycle was within the bottom $25 \%$ of the data (low diurnal power, diamonds in Fig. 9). Generally, the boundary layer at the SGP site reaches its maximum height between 20:00 and 23:00 UTC (15:00 and 18:00 CDT; Delle Monache et al., 2004; Liu and Liang, 2010) and, therefore, was not resolved in this dataset. However, these data do demonstrate that weekly periods with more consistent diurnal cycles in $N_{7-30 \mathrm{~nm}}$ were associated with deeper boundary layers that

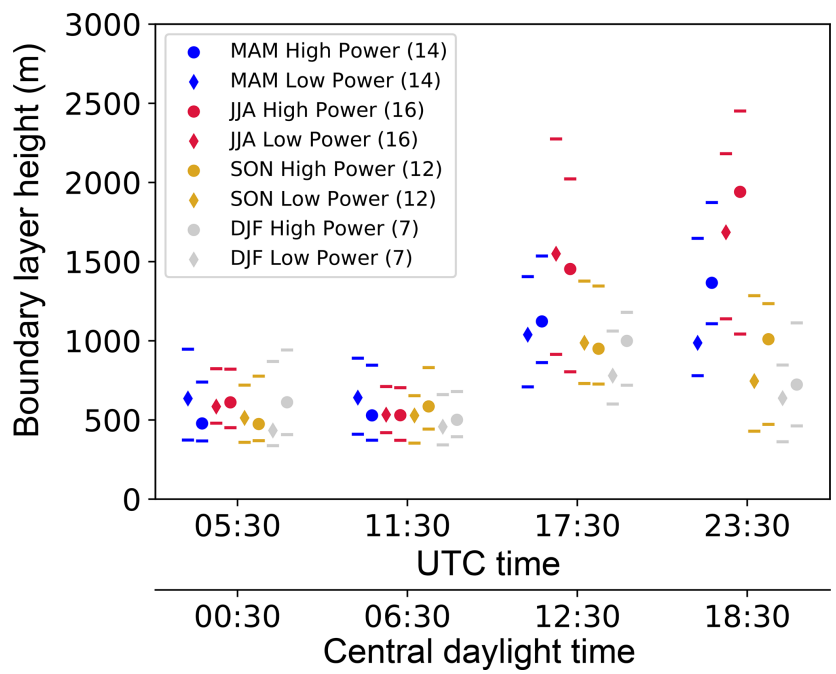

Figure 9. Diurnal cycle of boundary layer heights at the SGP site for each season, as estimated from radiosonde data. The circles represent the median boundary layer height for the top $25 \%$ of the weekly data in terms of power associated with the diurnal cycle in $N_{7-30} \mathrm{~nm}$ (High Power). Similarly, the diamonds represent the median boundary layer height for the bottom $25 \%$ of the weekly data (Low Power). The horizontal lines above and below the circles and diamonds represent the 25 th and 75 th percentiles (interquartile ranges) for these data. The numbers in parentheses represent the number of weekly time periods used in this analysis. The abscissa offset for each radiosonde launch time is for viewing purposes and does not reflect any shift in timing for each of the four radiosonde launch times for the different seasons.

extended into the late afternoon and evening hours, as can be seen by the higher median heights at 23:30 UTC for all seasons. This suggests that boundary layer development may play an important role in the $N_{7-30 \mathrm{~nm}}$ diurnal cycle. However, the significant overlap in the boundary layer height interquartile ranges between weekly periods with strong and weak diurnal power also suggests that there are other significant factors, such as synoptic weather events and aerosol sources, that will impact the occurrence of consistent diurnal cycles in $N_{7-30} \mathrm{~nm}$. Both the evolution of the boundary layer at the SGP site and the shift in timing of the diurnal cycle of $N_{7-30 \mathrm{~nm}}$ found in this present study corroborates earlier work that suggested nucleation of new particles sometimes occurs in the free troposphere or residual layer and is observed at the surface when mixing processes transport these aerosol to the surface (e.g., Weingartner et al., 1999; Hallar et al., 2011; Chen et al., 2018). The seasonal shift in the timing of the $N_{7-30 \mathrm{~nm}}$ diurnal cycle may also be related to the seasonal shifts in insolation, including both the variation in sunrise times and intensity, and the resulting impacts on photochemical processes leading to the formation and growth of small aerosol particles (e.g., O'Dowd et al., 1999).

For $N_{30-140 \mathrm{~nm}}$, there was a weaker diurnal signal in all seasons (Fig. $7 \mathrm{f}-\mathrm{j}$ ). The timing of the peak concentrations 

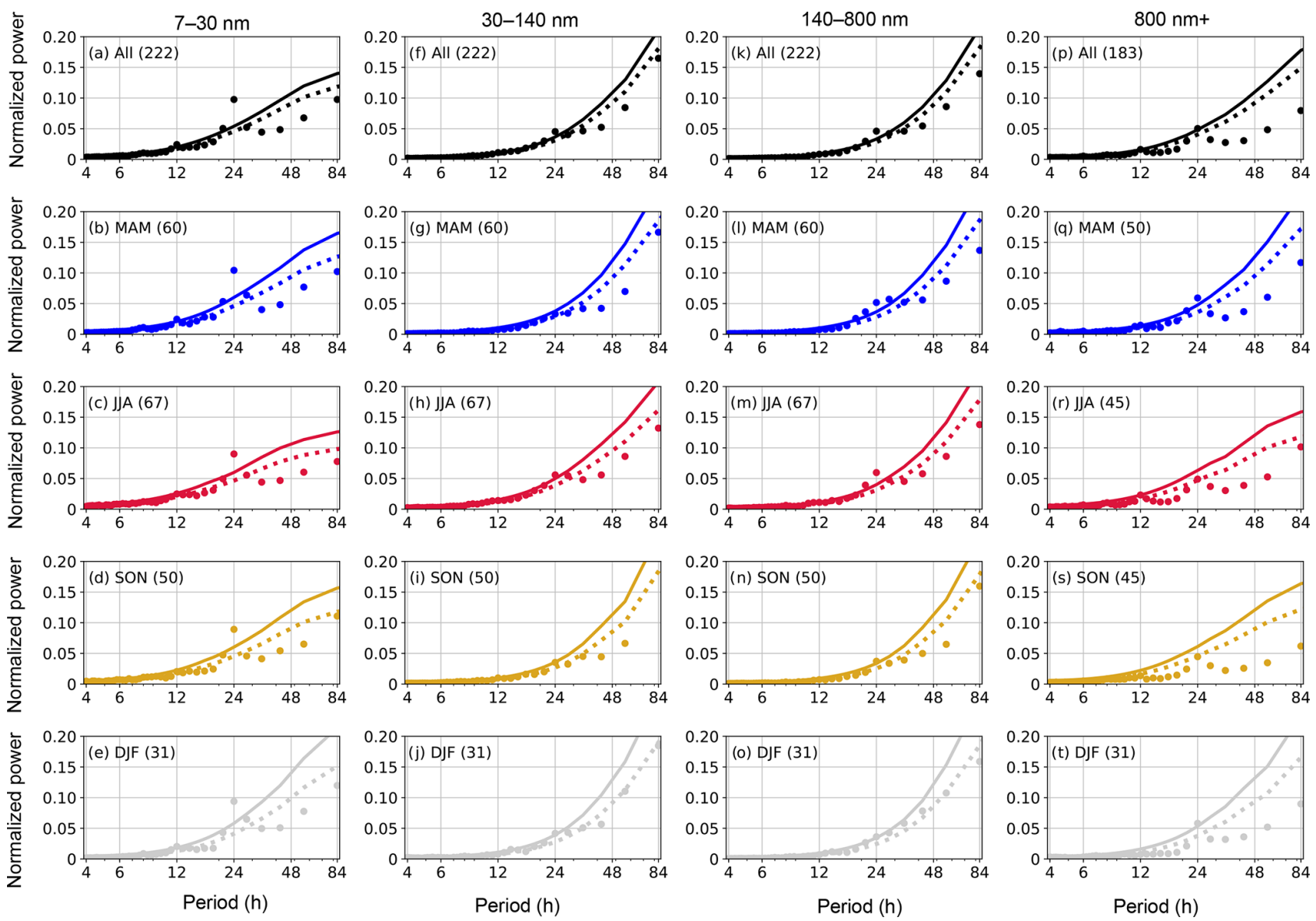

Figure 10. Normalized power spectra for $V_{7-30 \mathrm{~nm}}, V_{30-140 \mathrm{~nm}}, V_{140-800 \mathrm{~nm}}$, and $V_{800 \mathrm{~nm}+}$ for the entire period and by season. The descriptions of the symbols used are the same as in Fig. 5.

often occurred in the night and early morning hours, several hours after the peak in concentrations of $N_{7-30} \mathrm{~nm}$. This signal could be representative of the growth of the $N_{7-30 \mathrm{~nm}}$ aerosol mode to larger sizes. It is important to note that timing of peak concentrations of the diurnal cycle associated with these particles was more variable (Fig. 8b) than for $N_{7-30} \mathrm{~nm}$, with peak concentrations occurring at almost all times of the day. Therefore, the timing of and processes associated with the diurnal cycle for $N_{30-140 \mathrm{~nm}}$ were much less consistent throughout this dataset and could be related to a wide range of aerosol, radiative, and dynamical processes.

For $N_{140-800 \mathrm{~nm}}$, a more consistent diurnal cycle was present for all seasons (Fig. 7k-o). The timing of the $N_{140-800 \mathrm{~nm}}$ diurnal cycle was also generally consistent for all the seasons, with peak concentrations occurring between 08:00 and 16:00 UTC (03:00 and 11:00 CDT). These results are consistent with those for the integrated volume concentration for this mode $\left(V_{140-800 \mathrm{~nm}}\right.$, Figs. $10 \mathrm{k}-\mathrm{O}$ and $\left.11 \mathrm{c}\right)$, with volume concentrations providing a better comparison to prior studies that focused on optical properties and aerosol mass concentrations. For example, the timing of the diur-

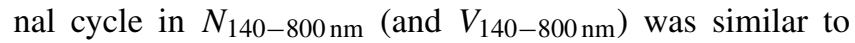

the reported diurnal cycle in the light absorption coefficient for $D_{\mathrm{p}}<10 \mu \mathrm{m}$ (Sheridan et al., 2001) and nitrate and organic aerosol mass concentrations for submicron particles from December 2011 through May 2011 (Parworth et al., 2015). To explain this diurnal cycle in particles between 140 and $800 \mathrm{~nm}$, data from an aerosol chemical speciation monitor (ACSM) at the SGP site (Ng et al., 2011) from $\mathrm{Au}-$ gust 2011 through December 2013 were used. The data were filtered to only include weekly data with power associated

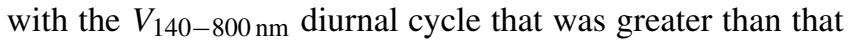
of red noise. The ACSM measured non-refractory submicron aerosol mass concentrations for several species, including nitrate, sulfate, ammonium, and organic aerosol. The timing of peak ACSM total mass concentrations (Fig. 12) aligns with the timing of peak concentrations in $V_{140-800 \mathrm{~nm}}$ and $N_{140-800 \mathrm{~nm}}$ (Figs. 11c and 8c, respectively). The ACSM data demonstrate that the diurnal cycle in $V_{140-800 \mathrm{~nm}}$ was related to nitrate and organic aerosol mass concentrations, although their relative contributions to the diurnal cycle varied by season. Organic aerosol had much stronger diurnal variations in JJA as compared to nitrate, while nitrate had stronger diurnal variations in DJF. Ammonium also had a similarly timed cy- 

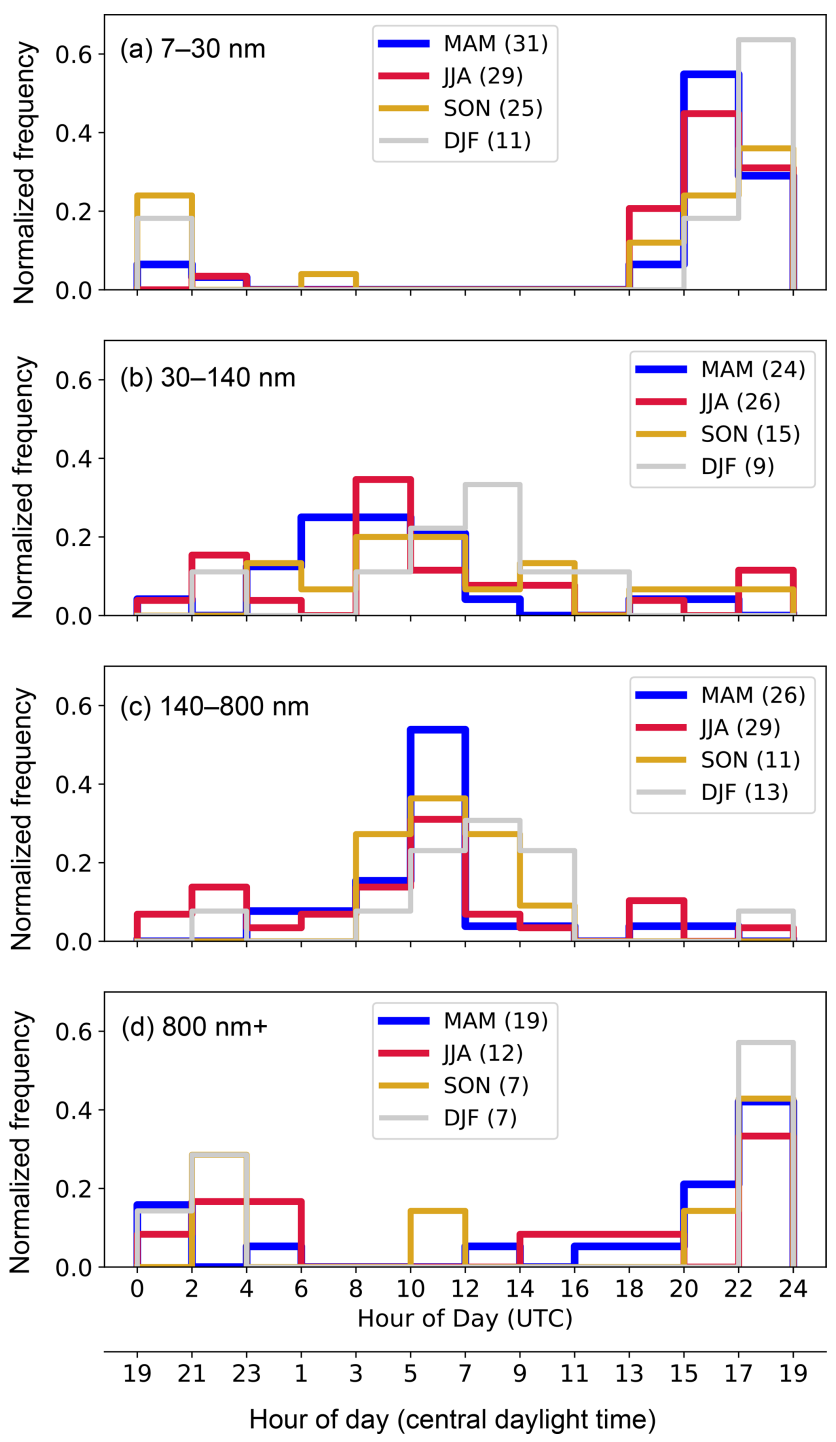

Figure 11. Normalized frequency of the daily time of peak concentrations associated with the $24 \mathrm{~h}$ cycle in the different modes of the aerosol volume size distribution. (a)-(d) represent $V_{7-30 \mathrm{~nm}}$, $V_{30-140 \mathrm{~nm}}, V_{140-800 \mathrm{~nm}}$, and $V_{800 \mathrm{~nm}+}$, respectively. The description of the figure is the same as in Fig. 6.

cle in MAM, SON, and DJF but with much lower anomalous concentrations. These trends represent a variety of aerosol processes, including temperature-dependent gas-to-particle partitioning, regional aerosol transport, and local emissions, and generally agree with the results of Parworth et al. (2015). Focused modeling studies and measurements are needed to further determine the specific and most important pathways leading to these diurnal cycles in aerosol concentrations.

Lastly, while there were no significant diurnal cycles in $N_{800 \mathrm{~nm}+}$ (Fig. 7p-t), there were significant peaks for the diurnal cycle associated with the integrated volume of particles within this size range $\left(V_{800 \mathrm{~nm}+}\right.$, Fig. $\left.10 \mathrm{p}-\mathrm{t}\right)$, with the strongest signals in MAM and DJF. The timing of peak

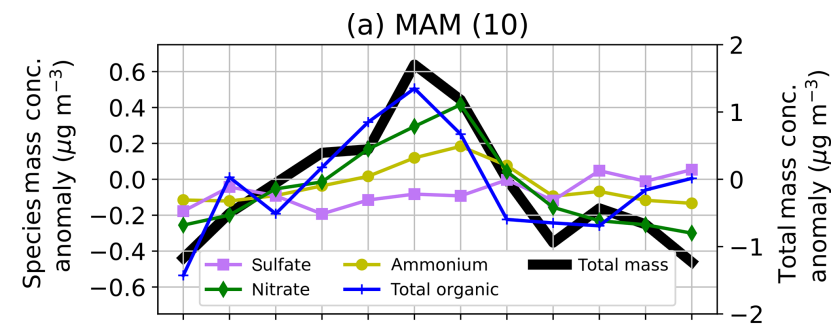

(b) JJA (19)

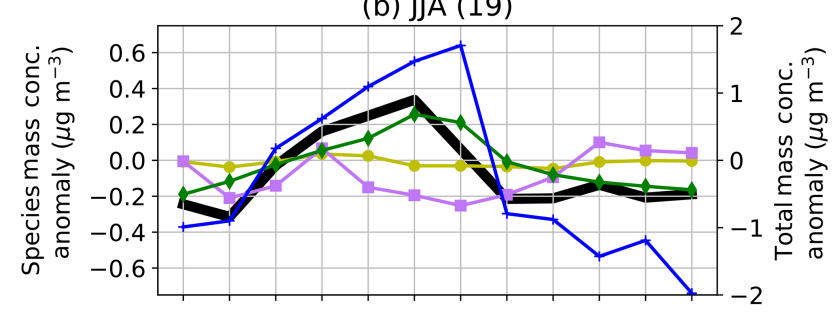

(c) SON (10)

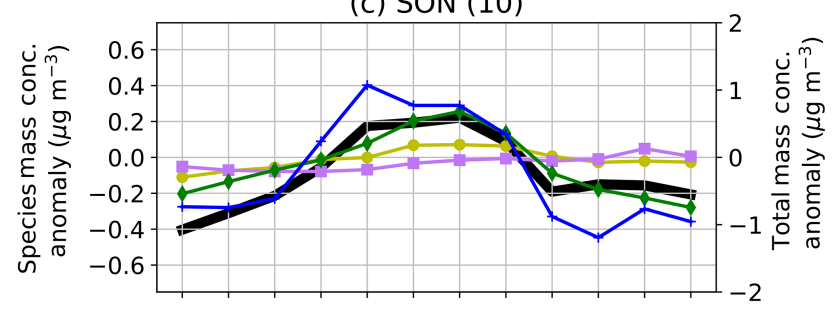

(d) DJF (9)

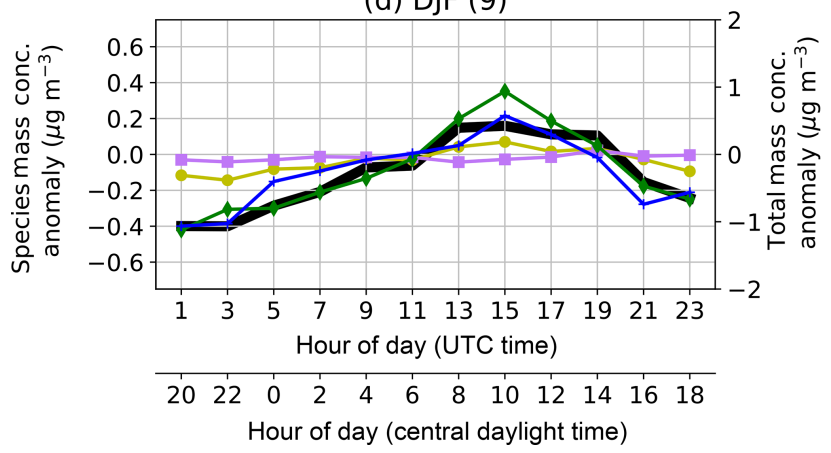

Figure 12. Diurnal cycle of aerosol mass concentration anomalies for sulfate, nitrate, ammonium, and organic aerosol species (left axes) and total mass concentrations (right axes) from the ACSM. The data were separated into seasons (a-d) and only included the weekly time periods in which the power associated with the $24 \mathrm{~h}$ cycle in integrated volume between 140 and $800 \mathrm{~nm}\left(V_{140-800 \mathrm{~nm}}\right)$ was greater than that of red noise. The number of these weekly time periods is shown in the parentheses in the panel titles.

concentrations associated with the diurnal cycle in $V_{800 \mathrm{~nm}+}$ was consistent amongst seasons and primarily occurred during the local evening hours, between 22:00 and 24:00 UTC (17:00 and 19:00 CDT, Fig. 11d). The fact that this signal was weaker in $N_{800 \mathrm{~nm}+}$ suggests that the diurnal signal was primarily associated with the largest particles within the coarse aerosol mode. This result aligns with the results of Andrews et al. (2011), which documented low Ångström exponent values in their spring and winter measurements at the SGP site, 


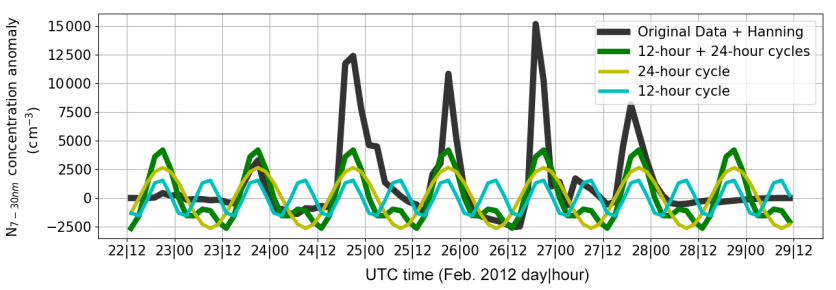

Figure 13. $N_{7-30 \mathrm{~nm}}$ for the weekly data chunk that had the highest power associated with the $12 \mathrm{~h}$ cycle (22-29 February 2012). The aerosol data are shown as a concentration anomaly from the seasonal mean (black). The anomaly data are broken down into the $12 \mathrm{~h}$ cycle component (cyan), the $24 \mathrm{~h}$ cycle component (yellow), and the combination of the 12 and $24 \mathrm{~h}$ cycles (green), as computed by the power spectral analysis.

which is often a signal for large dust aerosol. Also, surface meteorology data from the SGP site (ARM Climate Research Facility, 1995) during the same 5-year period demonstrate that surface winds, on average, reach a peak between 20:00 and 24:00 UTC, with stronger winds occurring in MAM and DJF. Therefore, we speculate that the timing of the $V_{800 \mathrm{~nm}+}$ diurnal cycle was related to the timing of strong wind conditions, which can loft large aerosol particles.

\subsubsection{The $12 \mathrm{~h}$ cycle of aerosol particles}

The strongest cycle with respect to red noise in the $N_{\mathrm{T}}$ data was the diurnal cycle (Fig. 5). However, there was also a statistically significant $12 \mathrm{~h}$ cycle present in some of these data, particularly in MAM and DJF (Fig. 5b, e). In general, the variability in $N_{\mathrm{T}}$ was caused by variability in $N_{7-30 \mathrm{~nm}}$, due to the high concentrations and high variability of particles in this size range. The peak concentrations of the $12 \mathrm{~h}$ cycle for all seasons occurred between 04:00 and 12:00 UTC (23:00 and 07:00 CDT) and between 16:00 and 24:00 UTC (11:00 and 19:00 CDT) for both $N_{\mathrm{T}}$ and $N_{7-30 \mathrm{~nm}}$ (not shown). The similarities between the timing of the peak concentrations of the $12 \mathrm{~h}$ cycles for $N_{\mathrm{T}}$ and $N_{7-30 \mathrm{~nm}}$ further demonstrate that the variability in $N_{7-30 \mathrm{~nm}}$ is the driving mechanism for the variability in $N_{\mathrm{T}}$.

The latter of the two daily peaks in concentrations associated with the $12 \mathrm{~h}$ cycle occurred at approximately the same time as the peak concentrations associated with the $24 \mathrm{~h}$ cycle (16:00-02:00 UTC or 11:00-21:00 CDT), suggesting that the 12 and $24 \mathrm{~h}$ cycles are related. To explain this relationship between the 12 and $24 \mathrm{~h}$ cycles, Fig. 13 shows the weekly aerosol data (22-29 February 2012) that had the strongest $12 \mathrm{~h}$ cycle, broken down into their 12 and $24 \mathrm{~h}$ cycle components. The peak concentrations of the $24 \mathrm{~h}$ cycle (yellow) clearly aligned with the peak concentrations of the aerosol data (black). However, the minimum in aerosol concentrations typically occurred directly before peak $N_{7-30 \mathrm{~nm}}$, as opposed to the $12 \mathrm{~h}$ shift that would be associated with a purely diurnal cycle. When including the $12 \mathrm{~h}$ cycle (cyan), the combination of the 12 and $24 \mathrm{~h}$ cycles (green) much better represented the aerosol time series (black). Therefore, the power associated with the $12 \mathrm{~h}$ cycle manifested from the different rates of growth and decay of aerosol number concentrations. The formation of $N_{7-30} \mathrm{~nm}$ occurred at a much faster rate than the loss of $N_{7-30} \mathrm{~nm}$. While the $12 \mathrm{~h}$ cycle primarily manifested from the sudden increase in number concentrations in this size range, it is important to note there were also time periods where a second peak in $N_{7-30 \mathrm{~nm}}$ occurred in the 04:00-12:00 UTC (23:00-07:00 CDT) time frame (e.g., 26-27 February 2012 in Fig. 13).

\subsection{Daily to weekly aerosol cycles}

Several prior studies have demonstrated weekly cycles in aerosol total number concentrations (Sheridan et al., 2001) and aerosol optical properties (Delene and Ogren, 2002; Sherman et al., 2015) at the SGP site. Spectral analyses aimed at resolving cycles on the order of 2 to $14 \mathrm{~d}$ required re-partitioning of the data into daily samples and $28 \mathrm{~d}$ data chunks. In order to achieve a larger number of $28 \mathrm{~d}$ continuous samples, the dataset was doubled to include the time period between 1 January 2007 and 1 January 2017. However, since the SMPS + APS size distribution data were not available during this extended time range, only the total aerosol number concentrations from the CPC were used. The CPC data for this extended time range were screened in the same manner as was done for the earlier analyses and as described in the Appendix. Figure 14 shows the power spectra for the entire period and by season for the expanded dataset. For the entire dataset, no cycles significant at the $99 \%$ confidence interval were found. However, the power spectra for MAM and SON had peaks just below this significance level for $7 \mathrm{~d}$ cycles, and the SON and DJF power spectra had peaks just missing this criterion for cycles lasting $\sim 3.5-5 \mathrm{~d}$. In JJA, there was no clear peak in the power spectrum above that of red noise on the timescales of 2-14d. These results are possibly related to the temporal cycles of synoptic conditions and air masses in the southern United States. At the SGP site, JJA is typically associated with large-scale ridges and weak synoptic flows (Coleman and Rogers, 2007) that would lead to stagnant air masses and no consistent cycles on these timescales. Using 4 years of springtime data, Lanicci and Warner (1991) determined that changing synoptic patterns lead to an approximately 1 week cycle in elevated mixed layers in the southern United States, and therefore this periodicity in synoptic patterns could help explain the weak weekly cycle in MAM. These results are also consistent with the higher intraseasonal variability observed in MAM, SON, and DJF for $N_{\mathrm{T}}$ (Fig. 2). Other studies have corroborated our hypothesis about the importance of synoptic-scale variability on aerosol concentrations at the SGP site. For example, Power et al. (2006) demonstrated significant differences in aerosol optical depth based on the classified air mass present 

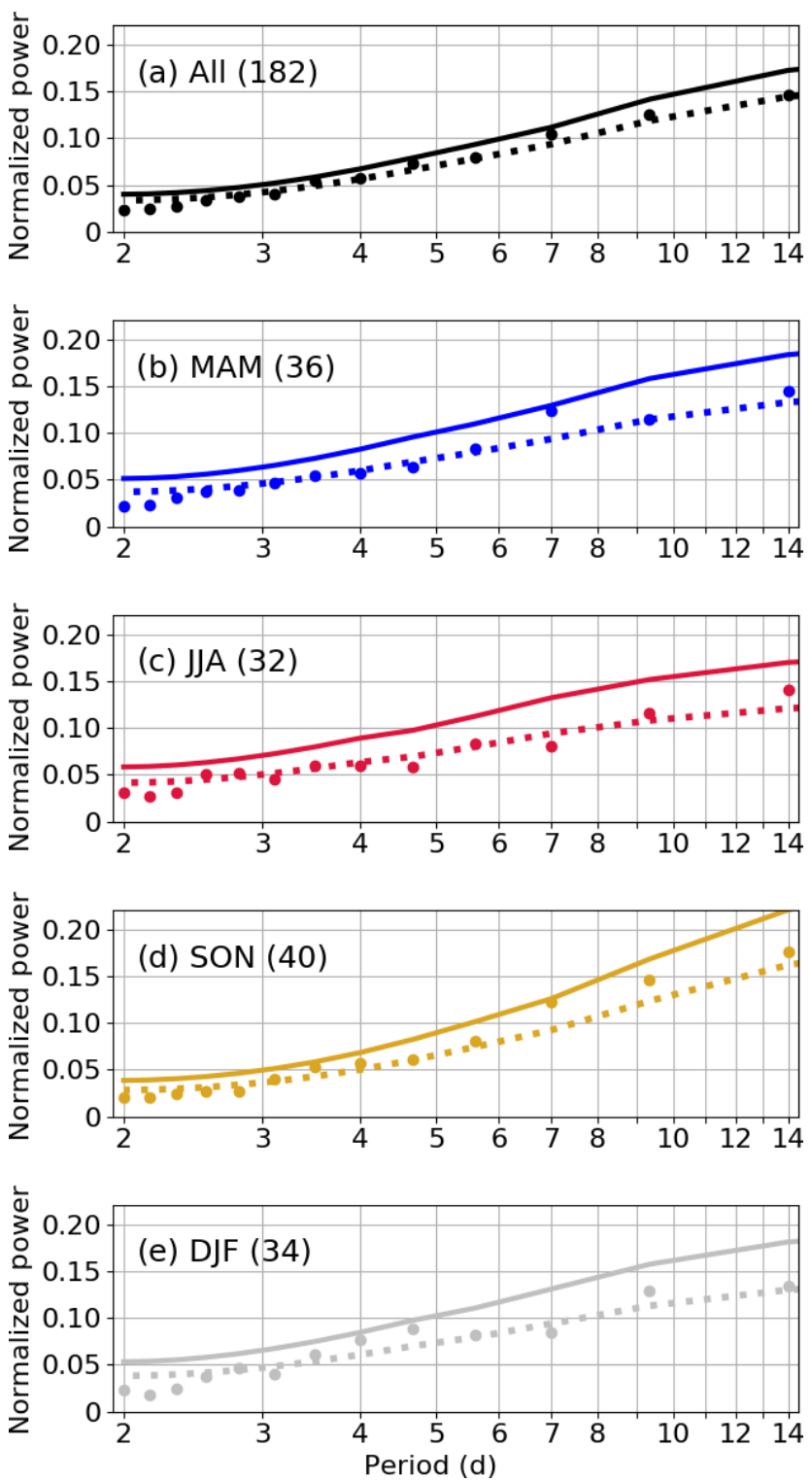

Figure 14. Normalized power spectra for $2-14 \mathrm{~d}$ cycles for the total aerosol number concentrations from the CPC for the entire period (a) and by season (b-e). The dots represent power associated with the data. The dashed lines represent an estimate of the red noise power spectrum for each dataset, and the solid lines represent the $99 \%$ significance testing level, as described in the text. The values in the parentheses are the number of $28 \mathrm{~d}$ data chunks used in this analysis.

at many locations across the United States, including at the SGP site.

\section{Conclusions}

The focus of this study is on 5-year (2009-2013) measurements from several instruments located at the Department of Energy's Atmospheric Radiation Measurement's South- ern Great Plains (SGP) site. These instrument datasets were merged to provide aerosol number size distributions for particles with diameters between $7 \mathrm{~nm}$ through $\sim 14 \mu \mathrm{m}$ and were also converted to surface area and volume size distributions (Marinescu et al., 2019). This quality-controlled dataset was used for two purposes. First, we provided key characteristics of the size distributions, including fits for four lognormal modes, both for the entire period and on a seasonal basis for the SGP site (a North American, rural, continental site). These observational data and analyses may be useful for validating models that explicitly represent aerosol processes. Furthermore, the characteristic aerosol size distributions presented in this study could also be used in a variety of applications, including more realistic representations of aerosol activation, radiation, and ice nucleation, especially in models that do not have detailed aerosol processes. Second, we quantified the variability in aerosol concentrations, with a focus on number concentrations, for a range of timescales from hourly to seasonal. Variability in the total number concentrations, as well as the integrated concentrations within specified size ranges that were associated with the different aerosol modes, was assessed.

In terms of seasonal differences, for total aerosol number concentrations $\left(N_{\mathrm{T}}\right)$, spring (MAM) and autumn (SON) had the largest mean concentrations, and winter (DJF) had the lowest mean concentrations. Summer (JJA) had the lowest variability in $N_{\mathrm{T}}$, as compared to the other seasons, suggesting more consistent background aerosol conditions during the summer months. Comparing the integrated number concentrations within the aerosol modes, the variability in total number concentrations $\left(N_{\mathrm{T}}\right)$ was driven by the large variability in the smallest particles $\left(N_{7-30} \mathrm{~nm}\right)$, which was likely related both to the presence of new particle formation events and the growth of these particles. JJA had the lowest mean concentrations of smallest particles $\left(N_{7-30} \mathrm{~nm}\right)$, possibly due to a coagulation sink that was associated with the fact that JJA had the highest mean concentrations of larger particles $\left(N_{30-140 \mathrm{~nm}}, N_{140-800 \mathrm{~nm}}\right.$, and $\left.N_{800 \mathrm{~nm}+}\right)$. The distributions of $N_{7-30 \mathrm{~nm}}$ and $N_{800 \mathrm{~nm}+}$ were more different between the seasons, as compared to $N_{30-140 \mathrm{~nm}}$ and $N_{140-800 \mathrm{~nm}}$. Therefore, the formation mechanisms and/or transport pathways of the smallest and largest particles have significant seasonal dependencies.

We used power spectral analyses to determine the presence of key temporal cycles, from hourly cycles through weekly cycles, within the aerosol data. A predominant $24 \mathrm{~h}$ (diurnal) cycle in each season was observed for $N_{\mathrm{T}}$, driven by concentrations of the smallest particles $\left(N_{7-30} \mathrm{~nm}\right)$. Peak concentrations associated with this diurnal cycle in $N_{7-30} \mathrm{~nm}$ and $N_{\mathrm{T}}$ generally occurred in the afternoon and evening hours, with a slight seasonal shift in the timing that was associated with seasonal shifts in boundary layer development and insola-

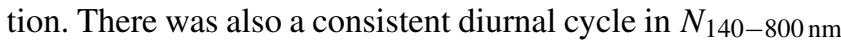
(and $V_{140-800 \mathrm{~nm}}$ ), with peak concentrations typically occurring between 08:00 and 16:00 UTC (03:00 and 11:00 CDT) 
in all seasons, consistent with the prior studies that have focused on aerosol optical properties and mass concentrations and is likely related to nitrate and organic aerosol mass concentrations. Because size-resolved measurements were limited to 5 years, cycles in aerosol number concentrations for longer periods (several-day to several-week cycles) were only tested for $N_{\mathrm{T}}$, for which 10 years of observations were used. Although there was no cycle that was sufficiently consistent to pass our $99 \%$ significance testing, there were several temporal scales that exhibited enhanced power, which varied by season and were likely related to synoptic-scale weather variability at the SGP site.

While this study provided key characteristics of aerosol size distributions at the SGP site and quantified the temporal variability of aerosol number concentrations within varying sizes and on a range of scales (hourly to seasonal), there are still uncertainties in attributing this variability to physical mechanisms, for which more in-depth analyses are required. For example, the recent New Particle Formation Study (NPFS) (Smith and McMurray, 2015; NPFS, 2013), which took place in April-May 2013 at the SGP site, was focused on understanding the pathways under which aerosol particles are formed and grow to larger sizes. Using the NPFS data, Hodshire et al. (2016) and Chen et al. (2018) presented several different growth pathways of newly formed particles during the 2013 spring period. Our study demonstrates with 5 years of observations that new particle formation and growth at the SGP site occur frequently throughout the year, and therefore, new particle formation and the subsequent growth pathways at the SGP site may be a more significant contribution to cloud condensation nuclei than previously appreciated. Classifying specific time periods when there are both consistent cycles in the data and hypotheses as to the mechanisms involved, as has been done in this study, can provide the temporal map for further detailed analyses using the wide range of instruments present at the SGP site or in future field campaigns.
Data availability. All data are publically available via the U.S. Department of Energy's Atmospheric Radiation Measurement (ARM) user facility data archive (Atmospheric Radiation Measurement (ARM), 1995, 2001, 2007, 2010, 2011, 2015) (https://doi.org/10.5439/1025220, https://doi.org/10.5439/1095386, https://doi.org/10.5439/1025259, https://doi.org/10.5439/1150275, https://doi.org/10.5439/1025152, and https://doi.org/10.5439/1025303), including the merged aerosol size distribution data (https://doi.org/10.5439/1511037, Marinescu et al., 2019). 


\section{Appendix A: Merged aerosol size distributions}

Five years (2009-2013) of data from three aerosol instruments at the ARM-SGP site were merged in order to create the aerosol size distribution dataset used in this study. One dataset was the aerosol size distribution data from the scanning mobility particle sizer (SMPS), part of the TDMA system, which were combined with size distribution data from the aerodynamic particle sizer (APS). The merged size distribution from those two instruments spanned the diameter (mobility) size range between $\sim 12 \mathrm{~nm}$ and $\sim 14 \mu \mathrm{m}$ with 215 bins (Collins, 2010; ARM Climate Research Facility, 2010 and 2015). The other dataset contained total aerosol number concentrations from a TSI 3010 condensation particle counter (CPC; ARM Climate Research Facility, 2007 and 2011). Therefore, total aerosol number concentrations can be obtained from both the integrated SMPS + APS size distributions and the CPC measurements. Because there were very few particles larger than the upper limit of the SMPS + APS measurements and the CPC measured smaller particles than the SMP S+ APS, concurrent CPC data were used to extend the SMPS + APS size distributions from $\sim 12 \mathrm{~nm}$ down to $7 \mathrm{~nm}$ and to improve the representation of the aerosol size distribution at the smallest sizes, where the largest SMPS observation uncertainties exist. The details of the processing of these data are described here.

First, the CPC data were quality controlled. Data that were flagged by the ARM quality control as suspect or incorrect due to faulty instrumentation or operation were removed. Also, CPC data that were consistently lower than the concentrations from a collocated cloud condensation nuclei counter (single column, DMT Model 1) at the highest supersaturation available (typically $\sim 1 \%$ ) and CPC data with unrealistically small $\left(<200 \mathrm{~cm}^{-3}\right)$ or unrealistically large $\left(>100000 \mathrm{~cm}^{-3}\right)$ aerosol number concentrations were removed. The quality-controlled CPC data were then timeinterpolated to the midpoint time of each SMPS + APS measurement period $(\sim 45 \mathrm{~min})$. Then, the SMPS + APS data were quality controlled. Here, it is important to note that estimated corrections were made to the SMPS size distributions to account for potential particle losses due to diffusion in the inlet and system tubing. Corrections were not made to the APS size distribution data for possible particle losses within the inlet and system tubing, but it is expected that these losses are likely small for most of the APS size distribution. For example, experiments have shown approximately unit transmission efficiencies for particles with diameters up to $4 \mu \mathrm{m}$ for the SGP inlet system. For larger sizes where low particle counts make it difficult to characterize transmission efficiencies experimentally, modeled transmission efficiencies predict significantly increasing biases for particles with diameters greater than $\sim 10 \mu \mathrm{m}$ (Bullard et al., 2017). During the quality-control process, suspect or incomplete SMPS + APS data were removed. Suspect or incomplete SMPS+APS data included instances when
1. the CPC data were unavailable or incorrect during a given SMPS + APS measurement period;

2. the integrated number concentration from the SMPS + APS was unrealistic, as noted above;

3. large portions of the SMPS + APS size distribution were missing, which occurred sporadically due to shifts in the instrument voltage;

4. there were unrealistic peaks in the size distribution, particularly at large particle sizes; and

5. there were peaks in integrated number concentrations in the first measurement after the daily calibration, which were likely due to contamination from residual particles from the atomized calibration aerosol.

These checks resulted in the removal of $\sim 25 \%$ of the SMPS + APS distributions, with the majority of data removal due to not having simultaneous CPC and SMPS + APS measurements. Despite this reduction in data quantity, over 31700 size distributions remained, which equate to $\sim 3$ years of data during the 2009-2013 time period.

In order to synthesize the quality-controlled CPC and SMPS + APS measurements into one merged dataset, five steps were taken (Fig. A1). First, the SMPS + APS size distributions were extrapolated from their smallest size bin (usually $\sim 12 \mathrm{~nm}$ ) down to $7 \mathrm{~nm}$, the approximate smallest size for which the CPC observes a significant fraction of aerosol particles ( $\sim 10 \%$; Mertes et al., 1995). The five smallest available size bins in the SMPS + APS size distribution were fit with a polynomial of the functional form:

$\mathrm{d} N\left(D_{\mathrm{p}}\right)=a D_{\mathrm{p}}^{2}+b$,

where $a$ and $b$ are coefficients and $D_{\mathrm{p}}$ is the particle size bin diameter in $\mu \mathrm{m}$. The coefficients, $a$ and $b$, were determined via least squares regression for each SMPS + APS size distribution, and the resulting polynomial was used to extrapolate the size distribution down to $7 \mathrm{~nm}$ (Fig. A1, Step 1). Several functional forms were tested for this extrapolation, and the form in Eq. (A1) produced the best results. Since the CPC only detected a fraction of the particles less than $28 \mathrm{~nm}$, we also applied the CPC detection efficiencies from Mertes et al. (1995) to scale down the extrapolated size distributions (Step 2 in Fig. A1) in order to represent the sizeresolved distribution that the CPC would observe. Therefore, the integrated number concentration from the resulting SMPS + APS size distribution represents an estimate of the same quantity reported by the CPC. The integrated number concentrations from the SMPS + APS size distributions after Step 2 were compared to the CPC total number concentrations. Since these two instruments were generally unmonitored during their deployments, a number of unreported issues (e.g., clogging or a leak in the air flow) may have 
(a) $11-05-2013$ 00:55:28

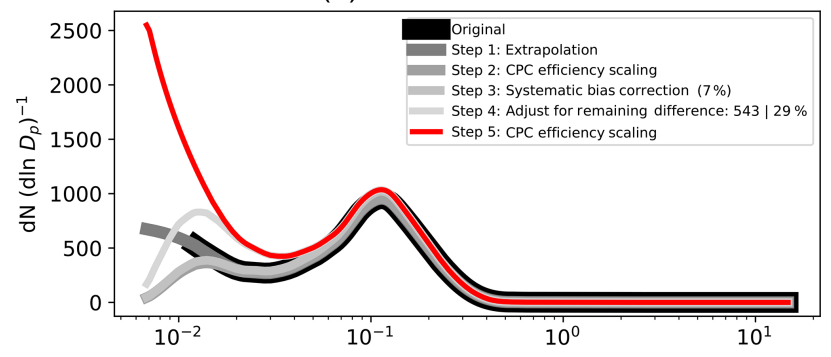

(b) 29-04-2013 10:46:24

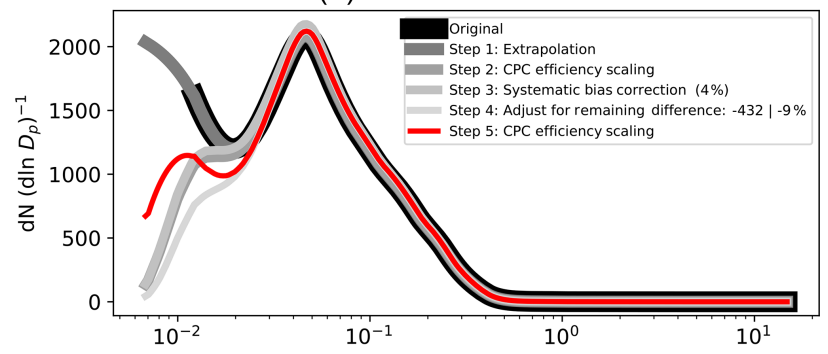

(c) 21-04-2013 18:59:12

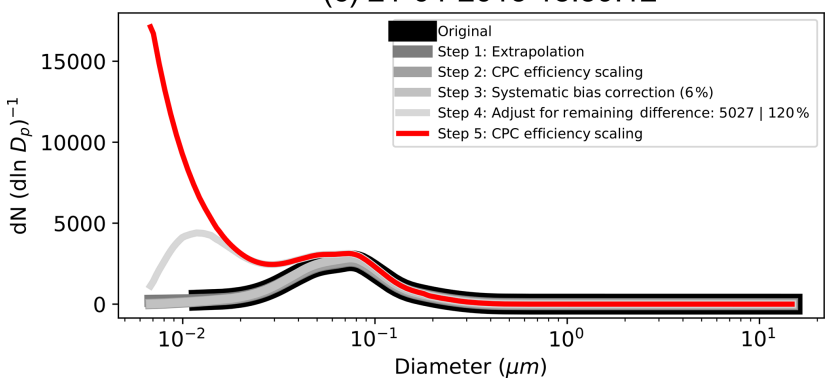

Figure A1. Three examples of the adjustments made to the original TDMA aerosol number size distributions and the final aerosol number size distribution post-adjustments (red).

caused the derived concentration measurements from either one of the instruments to drift for some extended periods of time. Therefore, in Step 3, the 2 week rolling median percentage difference between the two instruments was calculated for the entire time series and used to correct for any systematic drifts between the two instruments. This 2 week rolling median calculation excluded times between 18:00 and 24:00 UTC, when we would potentially expect large differences between the instruments due to new particle formation events and growth. Because of the higher uncertainties associated with the SMPS + APS total integrated number concentrations, the SMPS + APS size distribution was always scaled up or down to the CPC concentrations. This scaling factor was typically within $50 \%$ (median value of $7.3 \%$ for the entire dataset), except for two periods (JanuaryFebruary 2009 and September-December 2013) when the median percentage differences were consistently greater than $50 \%$.

After correcting for this systematic bias (Step 3), the remaining difference between the CPC and SMPS + APS total

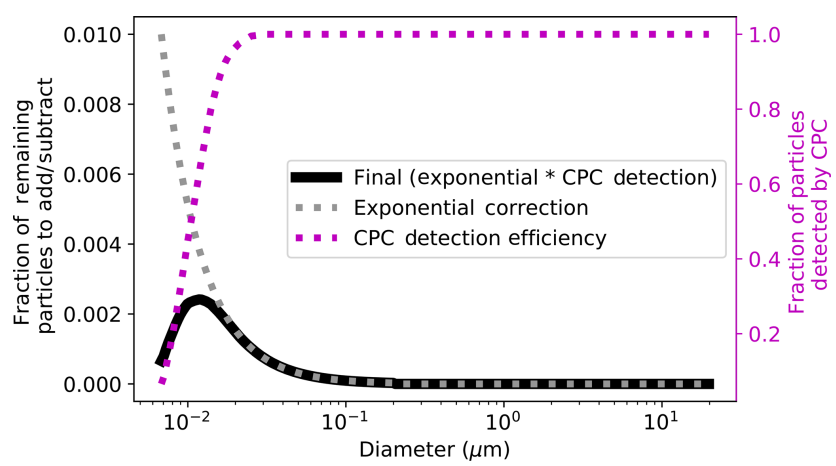

Figure A2. Fraction of particles to either add or remove from the size distribution during Step 4 of the adjustments (black), which was based on the multiplication of an exponential function (cyan) and CPC detection efficiencies (magenta, right axis).

number concentrations was used to adjust the SMPS + APS number size distribution, such that the integrated number concentration from the SMPS + APS size distribution equaled the CPC value. This difference in the total number concentration was applied to the SMPS + APS size distribution using an exponential function, only for sizes below the diameter associated with the 95th percentile of the cumulative integrated number concentration (median value of $\sim 200 \mathrm{~nm}$ ), and taking into account the CPC detection efficiencies (Fig. A2). An exponential function was chosen because there were much larger uncertainties in the observed number concentrations and diameters of the smallest particles in the size distribution and therefore, the need to correct particle counts was most likely associated with errors in the data for the smallest particle sizes. These uncertainties were associated with the possible loss of small particles within the inlet, sampling lines, and/or instrument due to evaporation or deposition to walls, the extrapolation of the SMPS+APS size distribution, uncertainties associated with the charging probabilities of the smaller particles in the SMPS + APS system, and small errors in the high voltage supplied in the SMPS, which can lead to substantial uncertainties in the sizing of the smallest particles observed. The aerosol size distribution above $\sim 200 \mathrm{~nm}$ was not changed in this step. The final correction function (Fig. A2, black line) was applied in an iterative manner, nudging the size distribution up or down in order to match the integrated number from the SMPS + APS size distributions to the CPC total number concentration (Step 4). The resulting aerosol size distributions after Step 4 were scaled back up by the reciprocal of the CPC detection efficiencies (Step 5) to represent an estimate of the true aerosol particle size distribution and number concentration at each time.

To validate the adjustment algorithm described above, the original and adjusted size distributions were compared to data from the New Particle Formation Study (NPFS) (Smith and McMurray, 2015; NPFS, 2013). NPFS took place at 

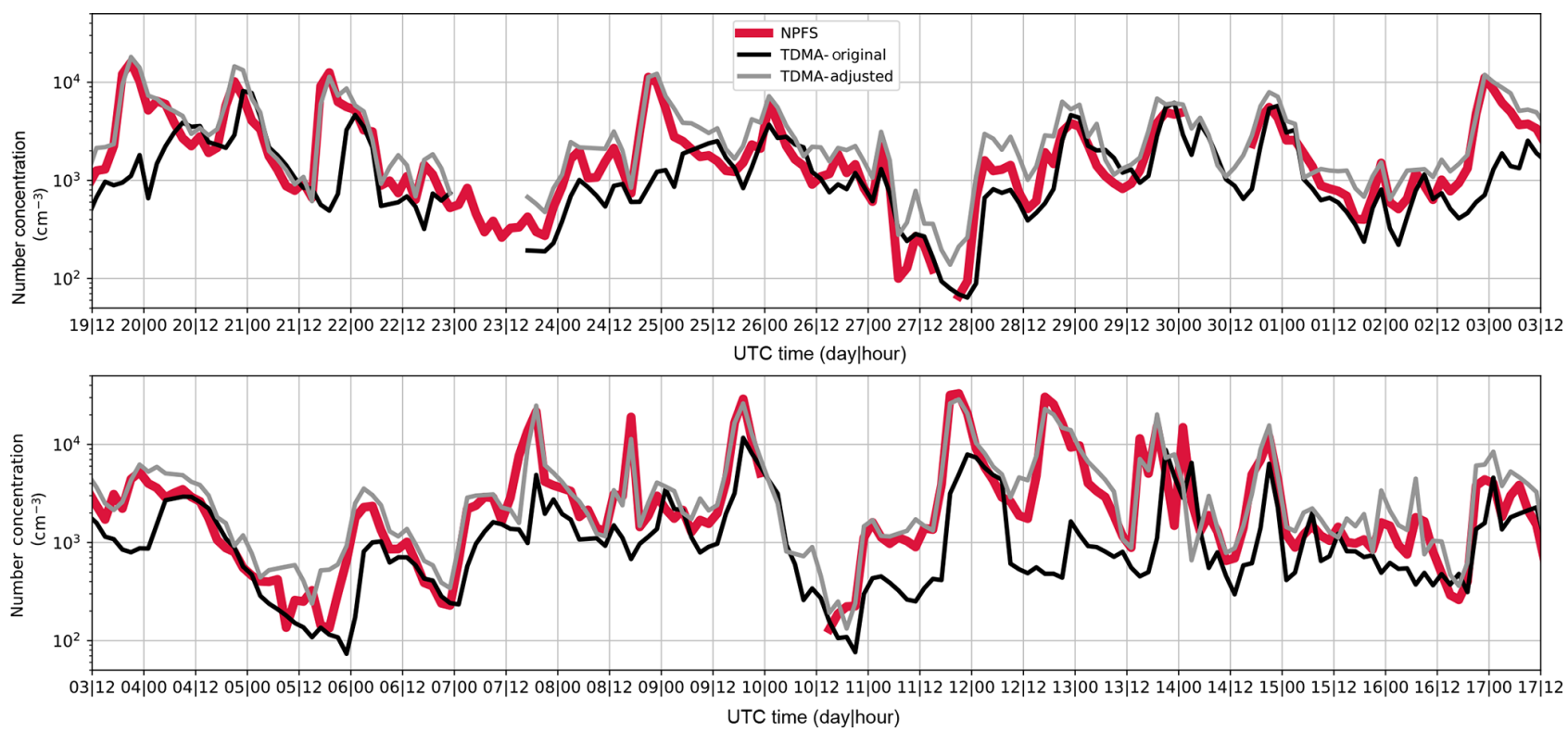

Figure A3. Time series of the integrated aerosol number concentrations between 7 and $30 \mathrm{~nm}$ in the New Particle Formation Study (red) and the SMPS+APS size distributions both before the adjustments (original, black) and after the adjustments (adjusted, gray). The dates included were 19 April 2013 through 17 May 2013.

the SGP site for $\sim 6$ weeks in April-May 2013, and during this study measurements of aerosol particle size distributions were measured down to $\sim 3 \mathrm{~nm}$ in the SGP guest facility, a few hundred meters away from the CPC and SMPS + APS measurements. We compared the integrated number concentrations for aerosol with diameters between 7 and $30 \mathrm{~nm}$ from the NPFS to the adjusted SMPS + APS size distributions during this period, since the majority of changes to the SMPS + APS size distributions occurred in this size range (e.g., Fig. A2). By incorporating the CPC data via the steps described above, the adjusted SMPS+APS distributions better captured the timing and magnitude of aerosol concentrations at these small particle sizes (Fig. A3). The correlation coefficient for this comparison improved from 0.37 to 0.89 from the original data to the adjusted data. The SMPS + APS size distribution data above $30 \mathrm{~nm}$ remained relatively unchanged, since the majority of the adjustments were applied below $30 \mathrm{~nm}$. This improvement of the SMPS + APS aerosol number size distribution data demonstrates the utility of having a suite of related aerosol instruments at the same site that can be compared and combined to provide a more comprehensive representation of aerosol characteristics. 
Supplement. The supplement related to this article is available online at: https://doi.org/10.5194/acp-19-11985-2019-supplement.

Author contributions. PJM performed the analyses presented. PJM, EJTL, and DC assisted with the data access. PJM, EJTL, DC, and SMK interpreted the raw aerosol data and developed the merged aerosol size distributions. PJM, EJTL, DC, SMK, and SCvdH assisted with the interpretation of the analyses, and PJM prepared the paper with contributions from all co-authors.

Competing interests. The authors declare that they have no conflict of interest.

Acknowledgements. All data were obtained from the Atmospheric Radiation Measurement (ARM) Program sponsored by the U.S. Department of Energy, Office of Science, Office of Biological and Environmental Research, Climate and Environmental Sciences Division. We would also like to acknowledge Sam Atwood for his assistance in fitting the size distribution data with multiple lognormal distributions.

Financial support. This research has been supported by the National Science Foundation Graduate Research Fellowship Program (grant no. DGE-1321845) and the U.S. Department of Energy's Atmospheric System Research, and Office of Science, Office of Biological and Environmental Research program (grant no. DESC0016051). Susan C. van den Heever and Peter J. Marinescu also received support from the NASA CAMP2Ex project (grant no. 80NSSC18K0149).

Review statement. This paper was edited by Fangqun Yu and reviewed by three anonymous referees.

\section{References}

Andrews, E., Sheridan, P. J., and Ogren, J. A.: Seasonal differences in the vertical profiles of aerosol optical properties over rural Oklahoma, Atmos. Chem. Phys., 11, 10661-10676, https://doi.org/10.5194/acp-11-10661-2011, 2011.

Atmospheric Radiation Measurement (ARM) Climate Research Facility: Surface Meteorological Instrumentation (MET). 2009-0101 to 2014-01-01, Southern Great Plains (SGP) Byron, OK (Extended) (E11), compiled by: Holdridge, D. and Kyrouac, J., Atmospheric Radiation Measurement (ARM) Climate Research Facility Data Archive, Oak Ridge, Tennessee, USA, last access: 22 August 2018, https://doi.org/10.5439/1025220, updated hourly, 1995.

Atmospheric Radiation Measurement (ARM) Climate Research Facility: Planetary Boundary Layer Height (PBLHTSONDE1MCFARL). 2006-12-31 to 2016-12-31, Southern Great Plains (SGP) Central Facility, Lamont, OK (C1), compiled by: Sivaraman, C. and Riihimaki, L., ARM Data Center, last access:
3 October 2018, https://doi.org/10.5439/1095386, updated hourly, 2001.

Atmospheric Radiation Measurement (ARM) Climate Research Facility: Aerosol Observing System (NOAAAOS). 2007-0519 to 2017-01-01, Southern Great Plains (SGP) Central Facility, Lamont, OK (C1), compiled by: Moyes, A., Sedlacek, A., Behrens, B., Kuang, C., Salwen, C., Hageman, D., Andrews, E., Senum, G., Uin, J., Boyer, M., Dubey, M., Smith, S., Springston, S., and Watson, T.: Atmospheric Radiation Measurement (ARM) Climate Research Facility Data Archive, Oak Ridge, Tennessee, USA, last access: 22 August 2018 https://doi.org/10.5439/1025259, updated hourly, 2007.

Atmospheric Radiation Measurement (ARM) Climate Research Facility: Tandem Differential Mobility Analyzer (TDMAAPSSIZE). 2009-01-01 to 2014-11-19, Southern Great Plains (SGP) Central Facility, Lamont, OK (C1), compiled by: Collins, D., Atmospheric Radiation Measurement (ARM) Climate Research Facility Data Archive, Oak Ridge, Tennessee, USA, last access: 17 January 2018, https://doi.org/10.5439/1150275, updated hourly, 2010.

Atmospheric Radiation Measurement (ARM) Climate Research Facility: Condensation Particle Counter (AOSCPC). 2011-03-10 to 2017-09-28, Southern Great Plains (SGP) Central Facility, Lamont, OK (C1), compiled by: Kuang, C., Salwen, C., Andrews, E., Boyer, M., and Springston, S., Atmospheric Radiation Measurement (ARM) Climate Research Facility Data Archive, Oak Ridge, Tennessee, USA, last access: 22 August 2018, https://doi.org/10.5439/1025152, updated hourly, 2011.

Atmospheric Radiation Measurement (ARM) Climate Research Facility: Tandem Differential Mobility Analyzer (TDMASIZE). 2009-01-01 to 2014-11-19, Southern Great Plains (SGP) Central Facility, Lamont, OK (C1), compiled by: Collins, D., Atmospheric Radiation Measurement (ARM) Climate Research Facility Data Archive, Oak Ridge, Tennessee, USA, last access: 17 January 2018, https://doi.org/10.5439/1025303, updated hourly, 2015.

Bullard, R. L., Kuang, C., Uin, J., Smith, S., and Springston, S. R.: Aerosol Inlet Characterization Experiment Report, U.S. Department of Energy ARM Climate Research Facility, DOE/SCARM-TR-191, https://doi.org/10.2172/1355300, 2017.

Chen, H., Hodshire, A. L., Ortega, J., Greenberg, J., McMurry, P. H., Carlton, A. G., Pierce, J. R., Hanson, D. R., and Smith, J. N.: Vertically resolved concentration and liquid water content of atmospheric nanoparticles at the US DOE Southern Great Plains site, Atmos. Chem. Phys., 18, 311-326, https://doi.org/10.5194/acp18-311-2018, 2018.

Coleman, J. S. M. and Rogers, J. C.: A synoptic climatology of the Central United States and associations with pacific teleconnection pattern frequency, J. Climate, 20, 3485-3497, https://doi.org/10.1175/JCLI4201.1, 2007.

Collins, D: Tandem Differential Mobility Analyzer/Aerodynamic Particular Sizer (APS) Handbook, U.S. Department of Energy ARM Climate Research Facility, DOE/SC-ARM-TR-090, 2010.

Dal Maso, M., Kulmala, M., Riipinen, I., Wagner, R., Hussein, T., Aalto, P. P., and Lehtinen, K. E. J.: Formation and growth of fresh atmospheric aerosols: eight years of aerosol size distribution data from SMEAR II, Hyytiälä, Finland, Boreal Environ. Res., 10, 323-336, 2005. 
Dal Maso, M., Sogacheva, L., Aalto, P. P., Riipinen, I., Komppula, M., Tunved, P., Korhonen, L., Suur-Uski, V., Hirsikko, A., Kurtén, T., Kerminen, V.-M., Lihavainen, H., Viisanen, Y., Hansson, H.-C., and Kulmala, M.: Aerosol size distribution measurements at four Nordic field stations: identification, analysis and trajectory analysis of new particle formation bursts, Tellus B, 59, 350-361, https://doi.org/10.1111/j.1600-0889.2007.00267.x, 2007.

Delene, D. J. and Ogren, J. A.: Variability of Aerosol Optical Properties at Four North American Surface Monitoring Sites, J. Atmos. Sci., 59, 1135-1150, https://doi.org/10.1175/15200469(2002)059<1135:VOAOPA > 2.0.CO;2, 2002.

Delle Monache, L., Perry, K. D., Cederwall, R. T., and Ogren, J. A.: In situ aerosol profiles over the Southern Great Plains cloud and radiation test bed site: 2. Effects of mixing height on aerosol properties, J. Geophys. Res.-Atmos., 109, 1-9, https://doi.org/10.1029/2003JD004024, 2004.

Fridlind, A. M., Li, X., Wu, D., van Lier-Walqui, M., Ackerman, A. S., Tao, W.-K., McFarquhar, G. M., Wu, W., Dong, X., Wang, J., Ryzhkov, A., Zhang, P., Poellot, M. R., Neumann, A., and Tomlinson, J. M.: Derivation of aerosol profiles for MC3E convection studies and use in simulations of the 20 May squall line case, Atmos. Chem. Phys., 17, 5947-5972, https://doi.org/10.5194/acp17-5947-2017, 2017.

Gilman, D. L., Fuglister, F. J., and Mitchell, J. M.: On the Power Spectrum of "Red Noise", J. Atmos. Sci., 20, 182-184, https://doi.org/10.1175/15200469(1963)020<0182:OTPSON>2.0.CO;2, 1963.

Hallar, A. G., Lowenthal, D. H., Chirokova, G., Borys, R. D., and Wiedinmyer, C.: Persistent daily new particle formation at a mountain-top location, Atmos. Environ., 45, 4111-4115, https://doi.org/10.1016/j.atmosenv.2011.04.044, 2011.

Hodshire, A. L., Lawler, M. J., Zhao, J., Ortega, J., Jen, C., YliJuuti, T., Brewer, J. F., Kodros, J. K., Barsanti, K. C., Hanson, D. R., McMurry, P. H., Smith, J. N., and Pierce, J. R.: Multiple new-particle growth pathways observed at the US DOE Southern Great Plains field site, Atmos. Chem. Phys., 16, 9321-9348, https://doi.org/10.5194/acp-16-9321-2016, 2016.

Jefferson, A., Hageman, D., Morrow, H., Mei, F., and Watson, T.: Seven years of aerosol scattering hygroscopic growth measurements from SGP: Factors influencing water uptake, J. Geophys. Res.-Atmos., 122, 9451-9466, https://doi.org/10.1002/2017JD026804, 2017.

Lanicci, J. M. and Warner, T. T.: A Synoptic Climatology of the Elevated Mixed-Layer Inversion over the Southern Great Plains in Spring. Part II: The Life Cycle of the Lid, Weather Forecast., 6, 198-213, https://doi.org/10.1175/15200434(1991)006<0198:ASCOTE>2.0.CO;2, 1991.

Leith, C. E.: The Standard Error of Time-Average Estimates of Climatic Means, J. Appl. Meteorol., 12, 1066-1069, https://doi.org/10.1175/15200450(1973)012<1066:TSEOTA>2.0.CO;2, 1973.

Liu, S. and Liang, X. Z.: Observed diurnal cycle climatology of planetary boundary layer height, J. Climate, 23, 5790-5809, https://doi.org/10.1175/2010JCLI3552.1, 2010.

Marinescu, P. J., Levin, E. J. T., Collins, D., and Kreidenweis, S. M., SGP Merged Aerosol Size Distribution (CPC + SMPS + APS), U.S. Department of Energy ARM Data Center, Oak Ridge, Tennessee, USA, https://doi.org/10.5439/1511037, 2019.
Marinescu, P. J., van den Heever, S. C., Saleeby, S. M., Kreidenweis, S. M., and DeMott, P. J.: The Microphysical Roles of Lower-Tropospheric versus Midtropospheric Aerosol Particles in Mature-Stage MCS Precipitation, J. Atmos. Sci., 74, 3657-3678, https://doi.org/10.1175/JAS-D-16-0361.1, 2017.

Mertes, S., Schröder, F., and Wiedensohler, A.: The particle detection efficiency curve of the tsi-3010 cpc as a function of the temperature difference between saturator and condenser, Aerosol Sci. Technol., 23, 257-261, https://doi.org/10.1080/02786829508965310, 1995.

Ng, N. L., Herndon, S. C., Trimborn, A., Canagaratna, M. R., Croteau, P. L., Onasch, T. B., Sueper, D., Worsnop, D. R., Zhang, Q., Sun, Y. L., and Jayne, J. T.: An Aerosol Chemical Speciation Monitor (ACSM) for routine monitoring of the composition and mass concentrations of ambient aerosol, Aerosol Sci. Technol., 45, 770-784, https://doi.org/10.1080/02786826.2011.560211, 2011.

Nieminen, T., Kerminen, V.-M., Petäjä, T., Aalto, P. P., Arshinov, M., Asmi, E., Baltensperger, U., Beddows, D. C. S., Beukes, J. P., Collins, D., Ding, A., Harrison, R. M., Henzing, B., Hooda, R., Hu, M., Hõrrak, U., Kivekäs, N., Komsaare, K., Krejci, R., Kristensson, A., Laakso, L., Laaksonen, A., Leaitch, W. R., Lihavainen, H., Mihalopoulos, N., Németh, Z., Nie, W., O'Dowd, C., Salma, I., Sellegri, K., Svenningsson, B., Swietlicki, E., Tunved, P., Ulevicius, V., Vakkari, V., Vana, M., Wiedensohler, A., Wu, Z., Virtanen, A., and Kulmala, M.: Global analysis of continental boundary layer new particle formation based on longterm measurements, Atmos. Chem. Phys., 18, 14737-14756, https://doi.org/10.5194/acp-18-14737-2018, 2018.

NPFS: New Particle Formation Study 2013, available at: https: //www.arm.gov/research/campaigns/sgp2013npfs (last access: 20 August 2018), 2013.

O’Dowd, C., McFiggans, G., Creasey, D. J., Pirjola, L., Hoell, C., Smith, M. H., Allan, B. J., Plane, J. M. C., Heard, D. E., Lee, J. D., Pilling, M. J., and Kulmala, M.: On the photochemical production of new particles in the coastal boundary layer, Geophys. Res. Lett., 26, 1707-1710, https://doi.org/10.1029/1999GL900335, 1999.

Parworth, C., Fast, J., Mei, F., Shippert, T., Sivaraman, C., Tilp, A., Watson, T., and Zhang, Q.: Long-term measurements of submicrometer aerosol chemistry at the Southern Great Plains (SGP) using an Aerosol Chemical Speciation Monitor (ACSM), Atmos. Environ., 106, 43-55, https://doi.org/10.1016/j.atmosenv.2015.01.060, 2015.

Peppler, R. A., Bahrmann, C. P., Barnard, J. C., Laulainen, N. S., Turner, D. D., Campbell, J. R., Hlavka, D. L., Cheng, M.-D., Ferrare, R. A., Halthore, R. N., Heilman, L. A., Lin, C.-J., Ogren, J. A., Poellot, M. R., Remer, L. A., Spinhirne, J. D., Sassen, K., and Splitt, M. E.: ARM Southern Great Plains Site Observations of the Smoke Pall Associated with the 1998 Central American Fires, B. Am. Meteorol. Soc., 81, 2563-2591, https://doi.org/10.1175/15200477(2000)081<2563:ASGPSO>2.3.CO;2, 2000.

Pierce, J. R., Westervelt, D. M., Atwood, S. A., Barnes, E. A., and Leaitch, W. R.: New-particle formation, growth and climaterelevant particle production in Egbert, Canada: analysis from 1 year of size-distribution observations, Atmos. Chem. Phys., 14, 8647-8663, https://doi.org/10.5194/acp-14-8647-2014, 2014. 
Power, H. C., Sheridan, S. C., and Senkbeil, J. C.: Synoptic climatological influences on the spatial and temporal variability of aerosols over North America, Int. J. Climatol., 26, 723-741, https://doi.org/10.1002/joc.1277, 2006.

Saleeby, S. M., van den Heever, S. C., Marinescu, P. J., Kreidenweis, S. M., and DeMott, P. J.: Aerosol effects on the anvil characteristics of mesoscale convective systems, J. Geophys. Res.-Atmos., 121, 10880-10901, https://doi.org/10.1002/2016JD025082, 2016.

Seibert, P., Beyrich, F., Gryning, S.-E., Joffre, S., Rasmussen, A., and Tercier, P.: Review and intercomparison of operational methods for the determination of the mixing height, Atmos. Environ., 34, 1001-1027, https://doi.org/10.1016/S1352-2310(99)00349$0,2000$.

Sheridan, P. J., Delene, D. J., and Ogren, J. A.: Four years of continuous surface aerosol measurements from the Department of Energy's Atmospheric Radiation Measurement Program Southern Great Plains Cloud and Radiation Testbed site, J. Geophys. Res.-Atmos., 106, 20735-20747, https://doi.org/10.1029/2001JD000785, 2001.

Sherman, J. P., Sheridan, P. J., Ogren, J. A., Andrews, E., Hageman, D., Schmeisser, L., Jefferson, A., and Sharma, S.: A multi-year study of lower tropospheric aerosol variability and systematic relationships from four North American regions, Atmos. Chem. Phys., 15, 12487-12517, https://doi.org/10.5194/acp-15-124872015, 2015.

Sisterson, D. L., Peppler, R. A., Cress, T. S., Lamb, P. J., and Turner, D. D.: The ARM Southern Great Plains (SGP) Site, Meteorol. Monogr., 57, 6.1-6.14, https://doi.org/10.1175/AMSMONOGRAPHS-D-16-0004.1, 2016.

Sivaraman, C., McFarlane, S., Chapman, E., Jensen, M., Toto, T., Liu, S., and Fischer, M.: Planetary Boundary Layer (PBL) Height Value Added Product (VAP): Radiosonde Retrievals (August 2013, Version 1), U.S. Department of Energy ARM Climate Research Facility, DOE/SC-ARM/TR-132, 2013.
Smith, J. N. and McMurry, P. H.: New Particle Formation Study Final Campaign Report. Ed. by Robert Stafford, DOE ARM Climate Research Facility, DOE/SC-ARM-15-011, 2015.

USDA-NASS Oklahoma Field Office: Oklahoma Agricultural Statistics 2012, Oklahoma City, OK, available at: https://www. nass.usda.gov/ok (last access: 17 April 2019), 2012.

Wang, J., van den Heever, S. C., and Reid, J. S.: A conceptual model for the link between Central American biomass burning aerosols and severe weather over the south central United States, Environ. Res. Lett., 4, 015003, https://doi.org/10.1088/17489326/4/1/015003, 2009.

Weingartner, E., Nyeki, S., and Baltensperger, U.: Seasonal and diurnal variation of aerosol size distributions $(10<D<750 \mathrm{~nm})$ at a high-alpine site (Jungfraujoch $3580 \mathrm{~m}$ asl), J. Geophys. Res., 104, 809-826, https://doi.org/10.1029/1999jd900170, 1999.

Welch, P.: The use of fast Fourier transform for the estimation of power spectra: A method based on time averaging over short, modified periodograms, IEEE T. Audio Electroacoust., 15, 7073, https://doi.org/10.1109/TAU.1967.1161901, 1967.

Wilks, D. S.: Frequentist Statistical Inference (Chapter 5), in Statistical Methods in Atmospheric Science, Third Edition, Academic Press, Oxford, UK, 147, 2011.

Yu, F., Luo, G., Pryor, S. C., Pillai, P. R., Lee, S. H., Ortega, J., Schwab, J. J., Hallar, A. G., Leaitch, W. R., Aneja, V. P., Smith, J. N., Walker, J. T., Hogrefe, O., and Demerjian, K. L.: Spring and summer contrast in new particle formation over nine forest areas in North America, Atmos. Chem. Phys., 15, 13993-14003, https://doi.org/10.5194/acp-15-13993-2015, 2015. 